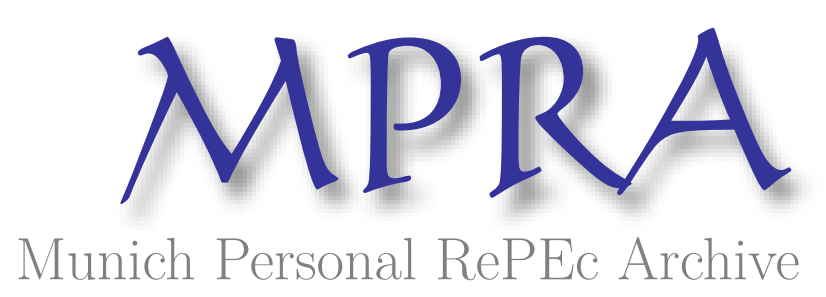

\title{
The Long-run Effects of HIV/AIDS in Kenya
}

Bruhns, Ramona

Economic Growth Center, Yale University

28 November 2006

Online at https://mpra.ub.uni-muenchen.de/952/

MPRA Paper No. 952, posted 29 Nov 2006 UTC 


\title{
The Long-run Effects of HIV/AIDS in Kenya
}

\author{
Ramona Bruhns*
}

November, 2006

\begin{abstract}
This essay analyzes the long-run economic effects of HIV/AIDS in Kenya, with emphasis on fertility, education and child labor. Human capital, which is built up through formal education and parental child-rearing, is the only input in production. Two aspects are central to the analysis: First, a mature AIDS epidemic causes massive premature adult mortality, thereby destroying existing human capital and reducing the labor force on a large scale. Second, the transmission of human capital to future generations is weakened, as children are left orphaned and surviving adults are correspondingly burdened. As a consequence, per capita income decreases and communities can less afford to raise and educate children as they did before the outbreak of the disease. The underlying theoretical model, in which it is assumed that parents raise and educate children for both financial and altruistic reasons, is calibrated using data for the period 1920 to 2000. The long-run effects of the disease, which depend heavily on parents' expectations about future mortality rates, are estimated for the years 2000-2040. Both human capital and per capita income grow significantly more slowly after the outbreak of the epidemic, while the incidence of child labor doubles for some periods. The level of fertility falls in the immediate aftermath of the outbreak, but can be significantly higher when the epidemic has reached a mature phase, depending on parents' expectations. Governmental interventions in the health sector in the early phase of the epidemic can strongly mitigate its adverse effects.
\end{abstract}

*Economic Growth Center, Yale University, 27 Hillhouse Ave., New Haven, CT 06511, USA. Email: ramona@bruhns.info

The author thanks the German Academic Exchange Service (DAAD) for support. 


\section{Introduction}

Kenya declared the HIV/AIDS epidemic a national disaster in 1999, 15 years after the first HIV/AIDS case had been reported. By that time, more than half a million Kenyans were estimated to have died of the disease, and some 2.5 million adults were infected. Other countries in Sub-Saharan Africa had reacted to the epidemic more than a decade earlier - notably Kenya's neighbor Uganda, which had declared AIDS a national disaster in 1986. Expectations in Kenya in 1999 were grim: the death rate was projected to rise from 560 persons per day in 2000 to 760 by 2005. ${ }^{1}$ While governmental interventions following the 1999 declaration seem to have borne some fruit, and the death rate had even been reduced to 300 per day by $2003,{ }^{2}$ the epidemic has not yet been brought under complete control.

Most new infections occur among young people, particularly women aged 15 to 24 and men aged 30 and younger. ${ }^{3}$ As 70 per cent of all Kenyan children are born to mothers younger than 30, high HIV/AIDS prevalence rates in this age group will strongly affect the way families raise and educate children. As the parents become ill, family income is reduced, either because they cannot work or because of the stigma towards those infected, who have difficulty finding employment. The high costs of treatment further increase the burden on the household's income. Children raised in families affected by HIV/AIDS often enjoy less parental guidance and care, and their education suffers, as they may have to work to support their parents and siblings. As therapies are often too costly, most victims die within 8-10 years of being infected, leaving their children orphans. By 2003, 37\% of all orphans were AIDS orphans, up from an estimated 3\% in 1990 and $22 \%$ in $1995 .{ }^{4}$ Even the education of those children whose parents are not ill suffers, as their teachers are often too sick to conduct their classes. The Kenya Teachers Service Commission reports that deaths among teachers more than tripled between 1995 and 1999, rising from 450 to 1500 per year. ${ }^{5}$ On average, $1.4 \%$ of all teachers are expected to die of HIV/AIDS yearly between 2000 and $2010 .^{6}$

As women of child-bearing age are strongly affected by the disease, and may transmit

\footnotetext{
${ }^{1}$ Source: http ://www.standwithafrica.org/hiv_aids/reality1.php

${ }^{2}$ Source: http ://www.aegis.com/news/afp/2003/AF031233.html

${ }^{3}$ Source: http ://www.unaids.org/EN/Geographical + Area/by + country/kenya.asp

${ }^{4}$ Sources: 1990 and 1995 figures: 'Children on the Brink',2002, U.N.AIDS, UNICEF and USAID collaboration. 2003 figure: 'Children on the Brink', 2004, U.N.AIDS, UNICEF and USAID collaboration

${ }^{5}$ Source: 'Education and HIV/AIDS: A window of hope', The World Bank, 2002

${ }^{6}$ Source: ibid.
} 
the virus on giving birth, the total number of children raised by a family is also expected to change. Yet only $30 \%$ of all women know that taking anti-retroviral drugs during late pregnancy can reduce the risk of Mother-To-Child-Transmission, according to the 'Kenya Demographic and Health Survey' conducted in 2003. Two different effects are possible: on the one hand, with potential mothers falling ill and dying and higher child mortality due to HIV/AIDS, completed familiy size could fall. On the other hand, families might respond to the rise in mortality by having more children, enough of whom would then survive to take care of their parents when these cannot care for themselves, either due to $\mathrm{HIV} / \mathrm{AIDS}$ or to old age.

Several studies have projected the impact of the epidemic in Kenya, focusing on economics, the health and education sectors, the development of the population size or specific population groups, like orphans or women. While macroeconomic empirical studies in the 1990s (e.g. Bloom and Mahal (1997)) suggest that the effects of the HIV/AIDS epidemics on the economies of Sub-Saharan African countries are small, more recent work suggests that the effects on specific countries or regions may be very damaging. Bell, Devarajan and Gersbach (2003), for example, simulate the South African economy for the years 1990-2080 and show that the effects of the epidemic will indeed be strong, with a distinct possibility of a collapse of the economy in the absence of government action. Arndt and Lewis (2000) use a shorter simulation period, namely, 1997-2010, and find that both total and per capita GDP are substantially lower in the face of the epidemic, compared to the counterfactual without HIV/AIDS. Bollinger, Stover and Nalu (1999) review several studies of the impact of AIDS in Kenya, and analyze the economic impact of the epidemic on that country's households, agriculture, firms and macroeconomy. They conclude by recommending measures aimed at mitigating the effects of the disease and emphasise the importance of governmental commitment to addressing HIV-related problems, and treating the disease as a 'national priority'.

Ferreira and Pessoa (2003) consider a continuous-time model with premature mortality due to HIV/AIDS where an individual's decision about schooling depends on her life expectancy. They arrive at the conclusion that HIV/AIDS has a strong impact on longterm growth, as individuals reduce formal education when their life expectancy falls. The model is applied to several African countries, and the authors show that schooling falls, on average, by half, while income falls by about a quarter in the presence of the HIV/AIDS epidemic. 
Corrigan, Glomm and Mendez (2004) consider a 2-generation OLG model where individuals can die prematurely before the start of the last period of life. They consider several scenarios, depending on the duration and strength of HIV/AIDS mortality shock. Growth rates in all scenarios fall when the epidemic breaks out, and recover if the shock is not permanent, that is, if morality rates subsequently return to their pre-epidemic level. The authors provide an extended version of their initial model in Corrigan, Glomm and Mendez (2005), where individuals live for up to three periods. The process of human capital formation is not only dependent on the parents' survival, but also on the time the child spends pursuing formal education rather than working. In addition to deciding about their own consumption and savings, parents, who are assumed to be altruistic, now also decide about their offsprings' schooling and consumption. If an individual is infected with the HIV virus, he also decides about spending on medical treatment, and does not save. The effects of the HIV/AIDS epidemic are large, reducing the current income after 10 generations by $5-45 \%$ of potential NO-AIDS income, depending of the scenario.

Young (2005) analyses South Africa, calibrating a Beckerian model of household behavior to Household Survey and Demographic and Health Survey Data. He then simulates various scemarios concerning household response to HIV/AIDS, and finds that per capita income can be larger in the presence of the epidemic, as fertility, and thereby the future labor force, are reduced, and this effect dominates the reduction in schooling orphans experience.

Bell et al. (2004) employ a three-generation OLG model to simulate the effects of the disease in Kenya up to 2050. Unlike the South African case, they find that the Kenyan economy is not threatened with a collapse, but GDP in the AIDS case is lower by about $40 \%$ in 2040 compared to the counterfactual without AIDS, and population is lower by about a third. Kenya's long-term problems are attributed to three interrelated factors: first, the 'weakening of the mechanisms through which human capital is transmitted from one generation to the next'; second, a sharp drop in the productivity of human capital in the decade following 1990; and third, the HIV/AIDS epidemic. To analyze the effects of these mechanisms on the Kenyan economy, Bell et al. (2004) focus on household decisions concerning education.

The purpose of the present essay is to extend their analysis by incorporating households' fertility decisions, as it seems realistic to assume that families react to exogenous shocks to mortality by adjusting not only the level of schooling, but also the number of children 
they intend to have in the first place. The essay will draw upon Bell et al. (2004), particularly where the model's structure and the data are concerned.

The essay is structured as follows: Section 2 gives a historical overview and discusses the data used. The model is introduced in section 3, and its calibration is presented in section 4. Several variations of projections of the Kenyan economy until 2040 are discussed in sections 5 and 6 , while the issue of public policy is taken up in section 7 . The issue of formulating and measuring social welfare in the presence of premature adult mortality is addressed in section 8 . The main results are stated in section 9, with conclusions in section 10 .

\section{Historical Overview and Data: 1920-2000}

At the beginning of the 20th century, Kenya was a British Protectorate officially called 'British East Africa'. Inland colonization by white settlers began around 1901, when the railway line connecting Mombasa and Lake Victoria was completed. By 1920, 9000 settlers were living in Kenya, and by 1950 their number had increased nearly 10-fold. ${ }^{7}$ Control over nearly all economic activity was concentrated in their hands, and the indigenous population was either employed as workers on the coffee farms, or engaged in mostly low-productivity traditional occupations. Legislation prevented the African population from purchasing and owning property in the highly fertile Kenyan Highlands and from taking part in government. It was only in 1944, that the first African became a member of the Colony's Legislative Council. ${ }^{8}$ The inequalities in economic and political power led to unrest, culminating in the Mau Mau Uprising between 1952 and 1960. While the uprising was suppressed by British troops, some of the Mau Mau's aims - like land reform - were attained in subsequent years.

In 1963, Kenya gained independence, and Jomo Kenyatta became its first president. He was succeeded by Daniel Arap Moi in 1978, who stayed in power until 2002. After Independence, several reforms were undertaken, especially in the spheres of land policy, the educational system, and the political system. Many of these reforms - particularly those regarding education - can be observed in the time series used in this essay, to which we now turn.

\footnotetext{
${ }^{7}$ Source. http://www.lonelyplanet.com/destinations/africa/nairobi/printable.htm

${ }^{8}$ Source: http://www.kenyalogy.com/eng/info/histo12.html
} 
Decadal data on the economies' output and demography for the years 1950 to 2000 are used, as well as data on the average years of schooling from 1920 onwards. A detailed discussion of the time series and revisions is given in Bell et al. (2004), on which this section draws. For the remainder of the essay, the round years will be used as time points, whereby the variable $t=1,2,3 \ldots, 14$ denotes the number of decades elapsed since the year 1900 , so that $t=10$ denotes the decade starting in the year 2000.

\subsection{Population}

During the period of interest, five censuses were conducted in Kenya, in the years 1948, 1962, 1969, 1979 and 1989. The United Nations Population Division, the World Bank (in the form of the World Development Indicators, WDI) and the Penn World Tables (PWT) provide secondary data on the Kenyan population and its structure. For the purposes of the calibration, data for the years 1950-1990 are used, with estimates for the nearest round date in the case of the Census figures.

The WDI does not report the total population for 1950, and its data for 1960 onwards are identical to the UN's, as are the PWT data. However, the population in the PWT for 1950 is higher than both the UN and Census data by $3.6 \%$ and $7.7 \%$ respectively. Bell et al. (2004) reconstruct the early part of the series and reject the PWT's estimates for that year.

Both the UN Population Division and the Censuses provide data on the age distribution. Except for the first and last group, which include infants aged 0-5 and people aged 65 and older, respectively, all 8 age groups span 10 years, their mid-points being 10, 20, 30, 40, 50 and 60. Age-groups will be denoted by the index $a=0, \ldots, 7$ and the size ${ }^{9}$ of an age group in period $t$ will be denoted by $N_{t}^{a}$. As both estimates are problem-ridden, a revised series was derived, in which the implicit age-specific death rates (defined below) are higher for those 35 and older than those implicit in of the original UN data. As a consequence, old cohorts are smaller, while young cohorts are relatively larger than the U.N.'s. Denote the mortality rate in age group $i$ over the period $t$ to $t+j-i,(j>i)$ in period $t$ by $q_{t}^{i, j}$. The age-specific death rate for age group $a$ is defined as the probability that a member of age group $a$ will not survive to become a member of age group $(a+1)$ 10 years later, and will be denoted by $q_{t}^{a, a+1}$. Mortality rates can then be computed from

\footnotetext{
${ }^{9}$ The unit of $N_{t}^{a}$ and of all other population data in the essay is $10^{3}$.
} 
Table 1: Population Tables

\begin{tabular}{|l|cccccc|}
\hline age group/year & 1950 & 1960 & 1970 & 1980 & 1990 & 2000 \\
\hline $0-4$ & 1040 & 1541 & 2294 & 3482 & 4458 & 4696 \\
$5-14$ & 1606 & 2317 & 3371 & 4951 & 7182 & 9006 \\
$15-24$ & 1192 & 1491 & 2167 & 3179 & 4715 & 6875 \\
$25-34$ & 882 & 1097 & 1381 & 2019 & 2979 & 4447 \\
$35-44$ & 634 & 784 & 983 & 1248 & 1833 & 2731 \\
$45-54$ & 441 & 542 & 677 & 857 & 1099 & 1634 \\
$55-64$ & 240 & 349 & 432 & 545 & 698 & 911 \\
$65+$ & 125 & 201 & 238 & 351 & 511 & 864 \\
\hline
\end{tabular}

the population tables as follows:

$$
q_{t}^{i, j}=1-\frac{N_{t+(j-i)}^{j}}{N_{t}^{i}} .
$$

In the remainder of the essay, the probability that a member of age group $a=2$ reaches age group $a=4$ will play a major role. It will be denoted by $\kappa_{t}$ :

$$
\kappa_{t} \equiv 1-q_{t}^{3,5}=\frac{N_{t+2}^{5}}{N_{t}^{3}} .
$$

\subsection{Output}

Both the Penn World Tables and the World Development Indicators provide data on aggregate output, with the PWT time series starting in 1950 and the WDI 10 years later. The PWT contains data on per capita GDP in constant purchasing power units with the base year 1995, as well as population data. As discussed in the previous section, the PWT population estimate for 1950 is implausibly high; so that total GDP for that year is derived using the revised estimate instead. The two series do not differ significantly for the following years, and the PWT series is chosen, being the longer of the two. As the purpose of the analysis is to derive long-term effects, short-term shocks to GDP are smoothed by forming 5-year moving averages. As can be seen from table 2, the Kenyan economy experienced a period of fast growth after Independence, but also a marked slowing down after 1990, with per capita GDP actually falling. For the remainder of the paper, GDP will be denoted by $Y_{t}$. 
Table 2: GDP in Kenya, 1950-2000

\begin{tabular}{|l|l|l|l|l|l|l|}
\hline Year & 1950 & 1960 & 1970 & 1980 & 1990 & 2000 \\
\hline GDP $\left(10^{7}\right)$ & 436 & 642 & 1089 & 2014 & 3076 & 3633 \\
\hline Average annual GDP growth (\%) & - & 3.9 & 5.4 & 6.3 & 4.3 & 1.7 \\
\hline
\end{tabular}

\subsection{Educational Attainment}

The educational system in Kenya underwent several major changes in the last century. The Department of Education was founded in 1911, but only 3\% of the country's African population had enjoyed any formal education by 1925 (Thias and Carnoy, 1972). Primary education was financed and organised by the communities and missionaries, and no common curriculum existed. Until Kenya gained independence in 1963, the African population received mostly technical and vocational training, as recommended by the Fraser Report of 1909. The Ominde Commission, set up in 1964, led to changes in the schooling system which aimed at increasing enrolments in secondary education. Up to 1966, primary and secondary education spanned 8 and 4 years respectively. Primary education was reduced to 7 years after 1966, but was extended again to 8 years in 1985, with all schools using the same curriculum. By 1973, school fees had been abolished for the first 6 years of primary education, following UNESCO's proposals. This led to high enrolment rates, particularly so in 1974 and 1979. As a consequence, the government hired a substantial number of new teachers, many of them poorly trained, thereby possibly reducing the quality - albeit not the quantity - of educational inputs. To finance these additional teachers, schools introduced a plethora of new, compulsory, fees, such as building and equipment levies. According to Nkinyangi (1982), "the cost of schooling as much as quadrupled in some ditricts" 10 after the levies were introduced. While some of these fees were abolished in subsequent years, primary schooling only became genuinely free in 2003.

Two data sets are used to determine the average years of completed schooling: the Censuses mentioned in section 2.1 and reports by the ministry of education. A very detailed description of the method is given in Bell et al. (2004), the results of which are set out in table 3. The variable $e_{t}$ denotes the average years of schooling of the school-age cohort in period $t$, expressed as a fraction of a 12-year schooling period.

\footnotetext{
${ }^{10}$ Nkinyanngi (1982), pp 204.
} 
Table 3: Educational Attainment

\begin{tabular}{|c|cccccccc|}
\hline Year & 1920 & 1930 & 1940 & 1950 & 1960 & 1970 & 1980 & 1990 \\
\hline Education $e_{t}$ & 0.047 & 0.080 & 0.134 & 0.201 & 0.367 & 0.458 & 0.520 & 0.570 \\
\hline
\end{tabular}

Source: Bell et al. (2004)

\subsection{School Fees}

Several surveys have studied household spending, and found that households spend about $3-5.5 \%$ of their total income on schooling. A summary of the studies' findings is given in table 4. School fees amounted to about $50 \%$ of total spending on education in 1994, and were abolished by 2003. As data on household income and expenditures is available until 1990, the costs of sending one child to school for one period, $\sigma_{t}$, can be computed from:

$$
\begin{array}{r}
\sigma_{t} e_{t} N_{t}^{1}=0.04 Y_{t} \Leftrightarrow \\
\sigma_{t} \equiv 0.04 Y_{t} /\left(e_{t} N_{t}^{1}\right) \quad \forall t \leq 9 .
\end{array}
$$

As $e_{t}, N_{t}^{1}$ and $Y_{t}$ are endogenous after 1990, $\sigma_{t}$ cannot be computed using the equation above for $t>9$. Instead, it will be assumed that all school-going costs remained constant after 1990, with the exception of school fees, which were abolished. From this, we set:

$$
\sigma_{t}=\sigma_{9} / 2 \quad \forall t>9
$$

Table 4: Household Spending on Education: Surveys

\begin{tabular}{|l|c|c|}
\hline Survey & School Fees & Spending on Education \\
\hline $\begin{array}{l}\text { Rural Household Survey Nyanza } \\
\text { Province } 1970 / 71\end{array}$ & 2.2 & \\
\hline $\begin{array}{l}\text { Urban Houshehold Budget Survey } \\
1993 / 94\end{array}$ & & $5.5^{a}$ \\
\hline Welfare Monitoring Survey II 1994 & $1.4^{b}$ & $2.9^{b}$ \\
\hline Welfare Monitoring Survey II 1994 & $2.0^{c}$ & $4.0^{c}$ \\
\hline Welfare Monitoring Survey III 1997 & 5.5 \\
${ }^{a}$ Recreation and Education \\
${ }^{b}$ Mean Household Expenditure \\
${ }^{c}$ Mean Household Expenditure - with Enrolled Children
\end{tabular}




\section{The Model}

The basic model describes household decisions concerning the bearing and rearing of children in the presence of premature adult mortality, for example, due to HIV/AIDS.

It is assumed that households consist of three generations, namely, children, parents and grandparents, each of whom is endowed with one unit of time. Children divide their time between working and learning, where the fraction of time assigned to education will be denoted by $e \in[0,1]$. Surviving parents work full-time, as do grandparents until the age of 65 . It is assumed that parents receive the income of the entire family, including that accruing to the grandparents, and then redistribute this income according to some set of social rules, which are described below.

For simplicity, it is assumed that parents (father and mother) are identical with respect to both their levels of human capital and their mortality rates. They raise and educate children in order to increase their own current consumption and to finance their old age. As investment in physical capital is ruled out by assumption, ${ }^{11}$ and grandparents work part-time only, they also rely on transfers from their children to finance their consumption. A fixed fraction $\chi \in(0,1)$ of the family's income is transferred to the grandparents. There are no bequests. Raising children is costly, and the better educated parents are, the more they spend on raising their children. School fees, which make up about half of the total costs of primary education in Kenya, were abolished only in 2003.

The temporal structure of the model is as follows: When they reach age group $a=2$ young adults form couples and decide on the number of children they intend to have and raise. They also enter into a binding contract on the education these children are to receive when they reach school-going age. If parents have perfect foresight about child mortality and if there is 'replacement fertility', as in Bell, Devarajan and Gersbach (2003), then a decision about fertility is equivalent to deciding about $N_{t}^{1}$, and we will take $N_{t}^{1}$ as the corresponding decision variable for the remainder of the essay. When parents are in age groups $a=2$ and $a=3$ their children go to school according to the decision made at birth, as stated in the contract; their level of schooling is $e_{t}$, and the level of human capital

\footnotetext{
${ }^{11}$ While households in Kenya can save, for example by purchasing land or other assets, most of this saving is precautionary saving. Retirement is not financed by savings, as shown by Hoddinott (1992): Old-age consumption is financed mostly through agricultural income, transfers from children, wages and business income. Other sources of income, such as pensions - which could be interpreted as a form of saving - make up at most $5.2 \%$ of the total income for poor and middle-income households, and $30 \%$ for richest decile. This suggests that pensions and other forms of savings are not available for the poor.
} 
(measured in efficiency units of labor) they attain upon reaching adulthood is denoted by $\lambda_{t+1}\left(e_{t}\right)$. In period $t+1$, the children start working themselves, and have their own children. When their parents reach age group $a=5$ in period $t+2$, they start receiving transfers from the younger generations. Therefore, the total number of 'young couples' in period $t$ will be $\left(N_{t}^{2}+N_{t}^{3}+N_{t}^{4}\right) / 2$, while the total number of 'old couples' in period $t+2$ will be $\left(N_{t+2}^{5}+N_{t+2}^{6}+N_{t+2}^{7}\right) / 2$.

It is assumed that the efficiency of a grown-up depends on the time she spent at school, the average efficiency of her parents and the productivity of the educational process [see Bell et al. (2004)]. If an individual does not spend any time at school, she will attain the basic minimum level of efficiency $\lambda=1$. It is assumed that adults in the two youngest age groups (i.e. $a=2$ and $a=3$ ) are involved in educating children, and that the educational technology is isoelastic with parameter $\epsilon$, as in Bell et al. (2004). The children which are going to school in period $t$ attain the following level of human capital in period $t+1$ :

$$
\lambda_{t+1}=2 z_{t} e_{t}^{\epsilon}\left(\frac{N_{t}^{2} \lambda_{t}+N_{t}^{3} \lambda_{t-1}}{N_{t}^{2}+N_{t}^{3}}\right)+1, \quad z_{t}, \epsilon>0
$$

where $z_{t}(>0)$ can be thought of as the strength of the mechanism for the inter-generational transmission of knowledge. The growth rate of the adults' level of efficiency in the case of full-time schooling is:

$$
g_{\lambda} \equiv \frac{\lambda_{t+1}-\lambda_{t}}{\lambda_{t}}=2 z_{t}\left(\frac{N_{t}^{2}+N_{t}^{3} \frac{\lambda_{t-1}}{\lambda_{t}}}{N_{t}^{2}+N_{t}^{3}}\right)+\frac{1}{\lambda_{t}}-1 .
$$

Note first that the growth rate will always be positive if previous generations enjoyed no schooling whatsoever, that is, ${ }^{12}$ if $\lambda_{t}=\lambda_{t+1}=1$. The growth rate $g_{\lambda}$ will be positive even for high levels of efficiency if $z_{t}$ is greater than 0.5. If, however, $z_{t}$ is lower than 0.5 , the growth rate will depend on the level of $\lambda_{t}$ : If $\lambda_{t}$ is sufficiently close to one, $g_{\lambda}$ will be positive, whatever be the level of $\lambda_{t}$, as $1 / \lambda_{t}$ is then sufficiently close to one. ${ }^{13}$ If the adults' level of efficiency is growing, however, the term in brackets will be lower than 1, while $1 / \lambda_{t}$ will be falling, so that $g_{\lambda}$ will eventually be zero or negative. A steady-state in $\lambda$ can arise if $z_{t}$ is stationary, with the steady-state level of efficiency being $\lambda^{*}=1 /\left(1-2 z_{t}\right)$. Note that in a steady-state with respect to $\lambda$, population growth plays no role, as the term in brackets in (5) will be 1 in all periods when $\lambda_{t}=\lambda_{t+1}$. The temporal structure

\footnotetext{
${ }^{12}$ This result is valid not only for the case of full-time schooling, but also for all $e_{t+1}>0$.

${ }^{13}$ For $\lambda_{t}=1, g_{\lambda}$ is always positive, as $2 z_{t}\left(\frac{N_{t}^{2}+N_{t}^{3} \frac{\lambda_{t-1}}{\lambda_{t}}}{N_{t}^{2}+N_{t}^{3}}\right)+\frac{1}{1}-1>0$
} 
of the population pyramid, however, is important, as it influences the choice of $e_{t}$, and therefore also determines whether stationary value of $\lambda$ can be reached.

Income is generated through the production of a single, non-storable good. Let the efficiency of a school-age child be fixed at $\mu$. Assume, further, that those younger than 5 and older than 65 years of age, that is, age groups $a=0$ and $a=7$, do not work at all. Therefore, ignoring unemployment, the total labor supply (measured in efficiency units) of an extended family in period $t$ will be:

$$
L_{t}=\underbrace{N_{t}^{2} \lambda_{t}+N_{t}^{3} \lambda_{t-1}+N_{t}^{4} \lambda_{t-2}+N_{t}^{5} \lambda_{t-3}+N_{t}^{6} \lambda_{t-4}}_{\text {adult labor }}+\underbrace{N_{t}^{1}\left(1-e_{t}\right) \mu}_{\text {child labor }}
$$

The production function is assumed to exhibit constant returns to scale with respect to labor (measured in efficiency units). Given the long-term character of the model, assessing the effects of land use in the production function is essential. However, data on land use, development and quality is not available. While a data series on arable land is available at the FAO, and reaches back to 1960, it does not include any information on the quality of the land used, and no data are available for the years before 1960, nor are projections for the future. To keep matters simple, therefore, we assume that the amount of land available is constant, and shared by all adults. We also assume that households are autarchik.

$$
\begin{aligned}
Y_{t} & \equiv \frac{\alpha_{t}}{\left(N_{t}^{2}+N_{t}^{3}+N_{t}^{4}+N_{t}^{5}+N_{t}^{6}\right)^{A}} \cdot L_{t}=\theta_{t} \cdot L_{t} \\
& =\theta_{t} \cdot\left(N_{t}^{2} \lambda_{t}+N_{t}^{3} \lambda_{t-1}+N_{t}^{4} \lambda_{t-2}+N_{t}^{5} \lambda_{t-3}+N_{t}^{6} \lambda_{t-4}+N_{t}^{1}\left(1-e_{t}\right) \mu\right),
\end{aligned}
$$

where $A \geq 0, \alpha_{t}>0$. The factor $\theta_{t}\left(=\frac{\alpha_{t}}{\left(N_{t}^{2}+N_{t}^{3}+N_{t}^{4}+N_{t}^{5}+N_{t}^{6}\right)^{A}}\right)$, denotes the amount of output produced with one unit of efficient labor. It has two components: its denominator $\left(N_{t}^{2}+N_{t}^{3}+N_{t}^{4}+N_{t}^{5}+N_{t}^{6}\right)^{A}$ captures the fact that the total amount of land is fixed, and divided among all families equally. $\alpha_{t}$ describes the general level of economic productivity. It can change over time, for example, as a result of economic policy or macroeconomic shocks.

The only active decision-makers in the present setting are the (young) parents, and the decisions they make determine their level of consumption in the last phase of life, as well as the level of efficiency their offspring will attain as adults. For simplicity, assume that the parents' decisions do not influence mortality rates.

Assume that raising infants is free, so that the level of consumption of a family which has 
infants only is not influenced by their fertility decisions. Therefore, when making fertility decisions in period $t$, parents, who are in age groups $a=2,3$ consider their (expected) level of consumption while their children are going to school (denoted by $c_{1, t}$ ) and later, when they themselves are old, whereby only consumption in the first period of old age is considered for simplicity (denoted by $c_{2, t+2}$ ). The adults also possess altruism, which expresses itself not only through the expenditures on educating and raising children, but also in their concern for the children's future welfare. For simplicity, it is further assumed that the utility function is additively separable, whereby the level of utility of adults who die prematurely is normalized to zero. Following Bell et al. (2004), we choose the form:

$$
E_{t} U\left(c_{1, t}, c_{2, t+2}, e_{t}, N_{t}^{1}\right)=\beta_{0} \ln \left(c_{1, t}\right)+\beta_{1} \kappa_{t} \ln \left(c_{2, t+2}\right)+\frac{2 N_{t}^{1} \kappa_{t+1}}{N_{t}^{2}+N_{t}^{3}}\left(1-\lambda_{t+1}\left(e_{t}\right)^{-\eta}\right)
$$

where $\kappa_{t+k}, k=0,1$ is the parents' subjective estimate thereof at time $t$.

Note that by choosing

$$
\phi=\frac{2 N_{t}^{1} \kappa_{t+1}}{N_{t}^{2}+N_{t}^{3}}\left(1-\lambda_{t+1}\left(e_{t}\right)^{-\eta}\right)
$$

as the subutility function with respect to altruism and the education production function in (4), equilibria with $\lambda_{t}=1$ and $e_{t}=0 \forall t$ (poverty traps) are excluded by construction if $\epsilon<1$. To see this, differentiate the subutility function with respect to $e_{t+1}$, and evaluate this derivative for $e_{t}=0$ :

$$
\lim _{e_{t} \rightarrow 0} \frac{\partial \phi}{\partial e_{t}}=\infty \quad \forall \epsilon<1, \quad \forall \eta
$$

As will be shown in the following section, the model can only be calibrated by choosing $\epsilon<1$, so that poverty traps are indeed excluded. The step in the calibration needed to determine $\epsilon$ is independent of the choice of functional form for preferences, so that the result $\epsilon<1$ will be valid even if the utility function took a different form. Therefore, as long as the subutility function $\phi$ satisfies the condition $\lim _{e_{t} \rightarrow 0} \frac{\partial \phi}{\partial e_{t}}=\lim _{e_{t} \rightarrow 0} \frac{\partial \phi}{\partial \lambda_{t+1}} \frac{\partial \lambda_{t+1}}{\partial e_{t}}=$ $\lim _{e_{t} \rightarrow 0} \frac{\partial \lambda_{t+1}}{\partial e_{t}}=\infty$, no poverty trap will exist. Stationary equilibria with respect to $\lambda$, however, can still exist if the parents' choice of schooling and fertility satisfies the condition $\lambda=2 z_{t} e_{t}\left(\lambda, N_{t}^{2}, N_{t}^{3}, \ldots\right)^{\epsilon} \lambda+1 \forall t$. Note, however, that this also implies some kind of equilibrium with respect to population, so that $e_{t}\left(\lambda, N_{t}^{2}, N_{t}^{3}, \ldots\right)=e_{t+1}\left(\lambda, N_{t+1}^{2}, N_{t+1}^{3}, \ldots\right) \forall t$, which seems unlikely.

Consider a family that raises $N_{t}^{1}$ children in period $t$. Each pair of adults in the groups 
$a=2,3,4$ receives the same fraction of the family's total income:

$$
\begin{array}{r}
\frac{Y_{t}}{\left(N_{t}^{2}+N_{t}^{3}+N_{t}^{4}\right) / 2}=\theta_{t} \cdot \frac{2\left(N_{t}^{2} \lambda_{t}+N_{t}^{3} \lambda_{t-1}+N_{t}^{4} \lambda_{t-2}+N_{t}^{5} \lambda_{t-3}+N_{t}^{6} \lambda_{t-4}\right)}{\left(N_{t}^{2}+N_{t}^{3}+N_{t}^{4}\right) \cdot} \\
+\theta_{t} \cdot \frac{2 N_{t}^{1}\left(1-e_{t}\right) \mu}{\left(N_{t}^{2}+N_{t}^{3}+N_{t}^{4}\right)} .
\end{array}
$$

A fixed fraction $\chi \in[0,1]$ of the total output produced by adults is allocated to the grandparents $(a=5,6,7)$, who consume it. Assume that each child consumes $b \lambda_{t}$ units per decade, and that one unit of schooling costs $\sigma_{t}$ per child. Then the consumption of a young couple in period $t$ is:

$$
\begin{aligned}
c_{1, t}= & 2 \theta_{t}(1-\chi) \frac{\left(N_{t}^{2} \lambda_{t}+N_{t}^{3} \lambda_{t-1}+N_{t}^{4} \lambda_{t-2}+N_{t}^{5} \lambda_{t-3}+N_{t}^{6} \lambda_{t-4}\right)}{\left(N_{t}^{2}+N_{t}^{3}+N_{t}^{4}\right)} \\
+ & 2 \theta_{t}\left(1-e_{t}\right) \mu \frac{N_{t}^{1}}{\left(N_{t}^{2}+N_{t}^{3}+N_{t}^{4}\right)}-2 b \lambda_{t} \frac{N_{t}^{1}}{\left(N_{t}^{2}+N_{t}^{3}+N_{t}^{4}\right)}-2 \sigma_{t} e_{t} \frac{N_{t}^{1}}{\left(N_{t}^{2}+N_{t}^{3}+N_{t}^{4}\right)} .
\end{aligned}
$$

The share $\chi$ is divided equally among all old members of the family:

$$
c_{2, t+2}=2 \theta_{t+2} \chi \cdot \frac{\left(N_{t+2}^{2} \lambda_{t+2}+N_{t+2}^{3} \lambda_{t+1}+N_{t+2}^{4} \lambda_{t}+N_{t+2}^{5} \lambda_{t-1}+N_{t+2}^{6} \lambda_{t-2}\right)}{N_{t+2}^{5}+N_{t+2}^{6}+N_{t+2}^{7}} .
$$

When deciding about $N_{t}^{1}$ and $e_{t}$ parents can observe all relevant historical and current values of $N, \lambda$ and $e$, particularly $\lambda_{t}$ and $e_{t}$, and the mortality rates in period $t$. They also form expectations about future mortality rates, and hence expectations about $N_{t+k}^{a}$ for $a=2, \ldots, 7$, and $k=1,2,3,4$.

Assume that parents have perfect foresight about all the $q_{t}^{i, j}$ in all future periods $t+$ $1, t+2, \ldots$ They can also observe or deduce the levels of efficiency $\lambda_{t-2}, \lambda_{t-1}$ and $\lambda_{t}$ associated with age groups $a=5$ and $a=6$ in period $t+2$. All the other values needed to determine $c_{2, t+2}$, namely, $N_{t+2}^{2}$ and $N_{t+2}^{3}$ as well as $\lambda_{t+2}$ are unknown. The level of $N_{t+2}^{3}$ can be determined from $N_{t}^{1}$, which is endogenous, using $N_{t+2}^{3}=\left(1-q_{t}^{1,3}\right) N_{t}^{1}$. Similarly, $N_{t+2}^{2}=N_{t+1}^{1}\left(1-q_{t+1}^{1,2}\right)$. However, the level of $N_{t+1}^{1}$ is not known to the parents when they make their decisions. Therefore, parents must make conjectures about the future number of school-going children and about $e_{t+1}$, which will determine $\lambda_{t+2}$. Given the complexity of this structure, assume that parents use a simplifying rule: they expect the level of schooling to be stationary:

$$
E_{t} e_{t+1}=e_{t-1}
$$


and the number of school-age children raised by couples in $a=2$ and $a=3$ in period $t+1$ to be stationary too:

$$
\begin{gathered}
E_{t}\left(\frac{2 N_{t+1}^{1}}{N_{t+1}^{2}+N_{t+1}^{3}}\right)=\frac{2 N_{t-1}^{1}}{N_{t-1}^{2}+N_{t-1}^{3}} \\
\Leftrightarrow \quad E_{t} N_{t+1}^{1}=N_{t}^{1} \cdot \frac{E_{t} N_{t+1}^{2}+E_{t} N_{t+1}^{3}}{N_{t-1}^{2}+N_{t-1}^{3}} \equiv N_{t}^{1} \psi_{t} .{ }^{14}
\end{gathered}
$$

Note that $N_{t+1}^{2}$ appears in $\psi_{t}$, which is endogenous, as $N_{t+1}^{2}=N_{t}^{1}\left(1-q_{t}^{1,2}\right)$. For simplicity, however, the ratio $\psi_{t}$ will be computed from the population tables (e.g. table 1).

Using (4), (9) and (10), the couple's expected utility can be rewritten as a function of $N_{t}^{1}$ and $e_{t}$ as well as $E_{t} e_{t+1}$ and $E_{t} N_{t+1}^{1}$ alone. Its optimization problem at time $t$ is then formulated as follows:

$$
\begin{array}{ccc}
\max _{e_{t}, N_{t}^{1}} E_{t} U\left(e_{t}, N_{t}^{1} ; E_{t} e_{t+1}, E_{t} N_{t+1}^{1}, \cdot\right) & \text { subject to } & N_{\min } \leq N_{t}^{1} \leq N_{\max } \\
& \text { and } & 0 \leq e_{t} \leq 1
\end{array}
$$

This yields two first-order conditions as functions of $E_{t} e_{t+1}$ and $E_{t} N_{t+1}^{1}$ :

$$
\frac{\partial E_{t} U\left(\cdot ; E_{t} e_{t+1}, E_{t} N_{t+1}^{1}\right)}{\partial N_{t}^{1}} \text { and } \frac{\partial E_{t} U\left(\cdot ; E_{t} e_{t+1}, E_{t} N_{t+1}^{1}\right)}{\partial e_{t}}
$$

Together with (11) and (12) these yield, for an interior solution,

$$
\left.\frac{\partial E_{t} U(\cdot)}{\partial N_{t}^{1}}\right|_{E_{t} e_{t+1}=e_{t-1}, E_{t} N_{t+1}^{1}=N_{t}^{1} \psi_{t}}=0 \text { and }\left.\frac{\partial E_{t} U(\cdot)}{\partial e_{t}}\right|_{E_{t} e_{t+1}=e_{t-1}, E_{t} N_{t+1}^{1}=N_{t-1}^{1} \psi_{t}}=0 \text {, }
$$

which, in turn, yield the optimal levels of $N_{t}^{1}$ and $e_{t}$.

Note that in the present setup, there is no time-inconsistency regarding the parents' decisions about $e_{t}$, as their expectations about mortality rates are correct by assumption if there is no HIV/AIDS shock. That is, when their children reach school-going age, parents have no incentives to depart from the binding contract on $e_{t}$ which they made at

\footnotetext{
${ }^{14}$ An alternative specification, namely $E_{t} e_{t+1}=e_{t}$, and respectively $E_{t}\left(\frac{2 N_{t+1}^{1}}{N_{t+1}^{2}+N_{t+1}^{3}}\right)=\frac{2 N_{t}^{1}}{N_{t}^{2}+N_{t}^{3}}$ is not well-defined, and could lead to non-unique solutions. Assume, for example, that parents expect future fertility rates to be high and education to be low, and therefore choose a high fertility and low schooling themselves, so that the expectations are satisfied. If, however, parents had assumed that fertility would be low and education would be high, and would themselves had chosen a high level of $e_{t}$ and a low level of $N_{t}^{1}$, the expectations again would have been satisfied. The specification above, therefore, would have been satisfied in both cases, and an additional rule would be required to choose between all possible solutions.
} 
child-birth. If, however, the parents' expectations about mortality rates prove to be incorrect, that is, if there is an unexpected mortality shock like the outbreak of the HIV/AIDS epidemic after the children are born but before they reach school-going age, it is unlikely that the contractual level of $e_{t}$ is still optimal, from the parents' point of view. Therefore, $e_{t}$ might be open to renegotiation.

\section{Calibration}

The model presented in the previous section is calibrated to the data from section 2 . The data on output, population and education can be used to derive the adult's level of efficiency $\lambda_{t}$ in each past generation, the children's level of efficiency $\mu$, the factors $\epsilon, z_{t}, A$ and $\alpha_{t}$, which characterize the education and production functions, respectively, the social rules governing transfers to the old and to children, $\chi$ and $b$, and the parameters of the subutility functions, $\beta_{0}, \beta_{1}$ and $\eta$. This will be done in two steps: first, national aggregates will be used to compute $A, \epsilon, \mu, z_{t}, \alpha_{t}$ and $\lambda_{t}$. Second, the calibration of preferences will yield the values of $\beta_{0}, \beta_{1}, b, \chi$ and $\eta$.

\section{Step 1}

The first step of the calibration is identical to the one employed in Bell et al. (2004). As noted in section 2.3, only 3\% of all adult Africans had enjoyed any education by 1925 . Therefore, it seems safe to assume that in 1910, before the Department of Education was established, the general population had no education at all and their level of efficiency was $\lambda_{1}=1$, that is, the minimum possible. Following Bell et al. (2004), $\lambda_{2}$ is set to 1.01 . Using this as an initial condition and equation (4) yields a set of 8 equations describing the dynamics of the adults' level of efficiency:

$$
\lambda_{t}=2 z_{t-1} e_{t-1}^{\epsilon}\left(\frac{N_{t-1}^{2} \lambda_{t-1}+N_{t-1}^{3} \lambda_{t-2}}{N_{t-1}^{2}+N_{t-1}^{3}}\right)+1, \quad t=3, \ldots, 10
$$

While no data on $e_{10}$ are available yet, it seems reasonable to assume $e_{10}=0.621$ (see Bell et al. [2004]). The second condition used in the calibration gives the age groups' contribution to GDP, as stated in equation (7):

$$
Y_{t}=\theta_{t}\left(N_{t}^{2} \lambda_{t}+N_{t}^{3} \lambda_{t-1}+N_{t}^{4} \lambda_{t-2}+N_{t}^{5} \lambda_{t-3}+N_{t}^{6} \lambda_{t-4}+N_{t}^{1}\left(1-e_{t}\right) \mu\right), \quad t=5, \ldots, 10
$$

where $\theta_{t}=\frac{\alpha_{t}}{\left(N_{t}^{2}+N_{t}^{3}+N_{t}^{4}+N_{t}^{5}+N_{t}^{6}\right)^{A}}$. The system described by (15) and (16) consists of 14 equations and 25 unknowns: $\alpha_{t}$ for $t=5, \ldots, 10, \lambda_{t}$ and $z_{t}$ for $t=3, \ldots, 10$ as well as 
$\mu, A$ and $\epsilon$, which are assumed to have stayed constant over time. As the system is underdetermined, solving it is only possible by making assumptions about the values of some of the variables.

Beginning with 1940, adults had enjoyed at least one year of schooling on average (see table 3), which suggests that the measures undertaken in the education sector in the early phase of the century had started to bear fruit. Therefore, the first shift in $z_{t}$ is assumed to have taken place in 1940. The second shift came after Kenya abolished school fees and reformed the educational system, that is, for the decade starting 1980. While per capita GDP grew until 1990, it started to fall thereafter. Hence, we assume that $\alpha$ stayed constant until $t=9$, and dropped once, in $t=10$. With these assumptions, the total of 14 variables associated with $z_{t}$ and $\alpha_{t}$ is reduced to 5 :

$$
\begin{array}{r}
z_{2}=z_{3}, \quad z_{4}=z_{5}=z_{6}=z_{7}, \quad z_{8}=z_{9}=z_{10} \\
\alpha_{5}=\alpha_{6}=\alpha_{7}=\alpha_{8}=\alpha_{9}, \quad \alpha_{10}
\end{array}
$$

To anchor the system, it is still necessary to choose two more variables. To simplify the calculation, $\epsilon$ and $A$ are chosen exogenously, as the equations are linear in all other parameters. Solutions where $\epsilon<0.47$ or $\epsilon>0.62$ are not considered, as they yield either negative values of one of the parameters, or $\mu>1$, that is, the labor efficiency of a child is higher than that of an adult who did not enjoy any schooling. The exact value of $\epsilon$ chosen should reflect the parents' decisions regarding schooling. As these decisions are determined by their preferences, we now turn to their calibration.

Table 5: Households' choices of $e_{t}$ and $N_{t}^{1}$

\begin{tabular}{|c|c|c|c|c|c|c|c|c|}
\hline Year & 1920 & 1930 & 1940 & 1950 & 1960 & 1970 & 1980 & 1990 \\
\hline$e_{t}$ & 0.047 & 0.080 & 0.134 & 0.201 & 0.367 & 0.458 & 0.520 & 0.570 \\
\hline$N_{t}^{1}$ & & & & 1606 & 2317 & 3371 & 4951 & 7182 \\
\hline $2 N_{t}^{1} /\left(N_{t}^{2}+N_{t}^{3}\right)$ & & & & 1.55 & 1.79 & 1.90 & 1.91 & 1.87 \\
\hline
\end{tabular}

Source: Bell et al. (2004)

\section{Step 2}

Table 5 presents the households' decisions concerning education and fertility for the years 1950 to 1990 . As can be seen, an interior solution existed during the whole period ${ }^{15}$

\footnotetext{
${ }^{15}$ If the household decisions were corner solutions, this would imply that the social rule on $N_{\text {min }}$ required each family to raise at least 1.55 children. As such a high value of $N_{\min }$ is rather restrictive, it seems
} 
and the two conditions in (14) can be used to recover the preference parameters. For any given value of $\epsilon$ and ensuing values of $\mu, \lambda_{t}, z_{t}$ and $\alpha_{t}$, five parameters need to be determined through a calibration of the preferences, namely, $\eta, \chi, b, \beta_{0}$ and $\beta_{1}$. For computational reasons, solving the system is only possible if one chooses $\eta$ exogenously, using a grid search method. The other variables are calibrated using (14) for the years 1970 and 1990. A plethora of results exists for the different values of $\epsilon$ and $\eta$ : from all the possible results, one with $\beta_{0} / \beta_{1} \leq 1.01^{20}=1.22$ and $c_{1, t} / c_{2, t} \approx 1, \quad t=7,9$ is chosen. The first condition (i.e. $\beta_{0} / \beta_{1} \leq 1.01^{20}$ ) considers the the rate of pure impatience of individuals. While there are no studies estimating this rate for Kenya, the rate is between 0.25 and $0.5 \%$ p.a. in the U.S., according to Fullerton and Rogers (2003) and Altig et al. (1996). Consequently, we will irgnore all solutions where the pure impatiance lies above $1 \%$ p.a. in Kenya. The second condition, namely $c_{1, t} / c_{2, t} \approx 1$, implies that families choose a fairly smooth path of consumption in the two periods of life, apart from the eventuality of premature death, which is captured by the term $\kappa_{t+1}$ in (8). For all values of $A<0.04$ and $A>0.17$, no solutions satisfying the conditions above exist. Similarly, if $\epsilon<0.47$, the calibration yields $\mu>1$, that is, a child's level of labor efficiency is higher than that of an adult who enjoyed no schooling whatsoever, which does not seem realistic.

A continuum of results satisfying all conditions above exists. To keep the number of solutions manageable, we have chose a stepwidth of 0.01 for $A, \epsilon$ and $\eta$, which reduces the number of solutions to 27 . The summary statistics of all 27 solutions are set out in table 6.

Table 6: Calibration results: summary statistics

\begin{tabular}{|c|c|c|c|}
\hline Parameter & Min & Max & Average \\
\hline$A$ & 0.06 & 0.17 & 0.10 \\
$\epsilon$ & 0.52 & 0.54 & 0.53 \\
$\eta$ & 0.57 & 2.06 & 1.44 \\
$\mu$ & 0.35 & 0.69 & 0.54 \\
$\chi$ & 0.08 & 0.18 & 0.13 \\
Time Preference $^{a}$ & 0.49 & 0.99 & 0.72 \\
\hline Drop $^{b}$ in $\alpha_{t}$ & 18.28 & 19.13 & 18.64 \\
Drop $^{c}$ in $z_{t}$ & 43.18 & 45.92 & 44.79 \\
Drop $^{d}$ in $\lambda_{t}$ & 10.09 & 15.41 & 13.32 \\
${ }^{a}$ In $\%$ per year. \\
${ }^{b}$ Defined as $-\left(\alpha_{10}-\alpha_{9}\right) / \alpha_{9}$ in \% $\%$ in ${ }^{d}$ Defined as $\left(\lambda_{8}-\lambda_{9}\right) / \lambda_{8}$ in $\%$
\end{tabular}

reasonable to assume that 1.55 children per family, as raised in 1950, constitutes an interior solution. 


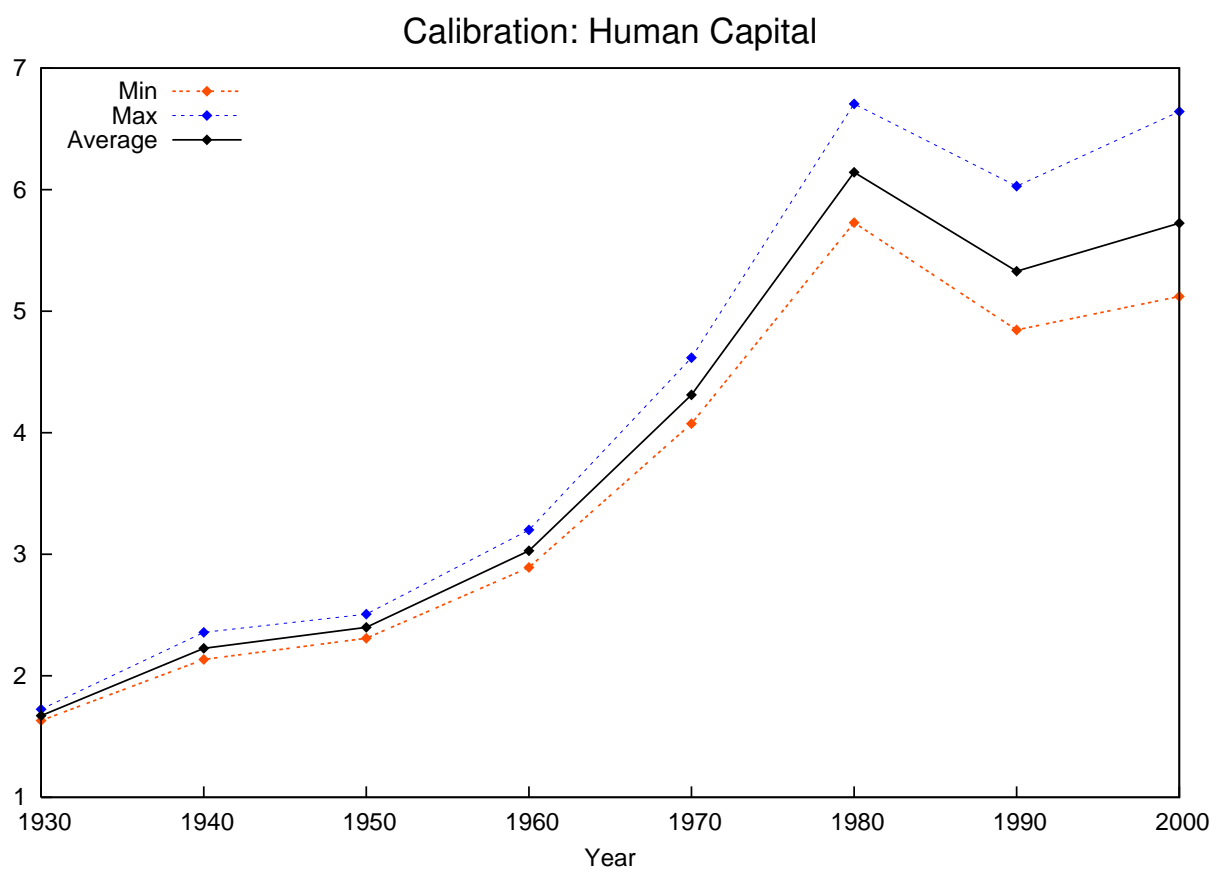

Figure 1: Calibration Results (All Calibrations)

Min., Max., and Average refer to the minimum, maximum and average value $\lambda_{t}$ takes over all calibrations.

A value of $A$ between 0.06 and 0.17 implies that, even if $\alpha_{t}$ stays constant, the productivity of one unit of efficient labor $\left(\alpha_{t} /\left(\sum_{a=2}^{6} N_{t}^{a}\right)^{A}\right)$ has fallen as population has grown. Working-age population (age groups 2-6) has more than tripled between 1950 and 1990, which implies a reduction in productivity of $7 \%$ to $21 \%$ during that period. In all solutions satisfying the conditions above, we get $\mu \in[0.35,0.69]$ that is, a child's labor efficiency is lower by at least 30\% than the efficiency of an uneducated adult. The transfer to the grandparents amounts to $8-18 \%$ of the total income from adult labor. This is somewhat lower than the grandparents' share of the population $\left(\frac{N_{t}^{5}+N_{t}^{6}+N_{t}^{7}}{\sum_{a=0}^{7} N_{t}^{a}} \approx 0.12\right.$ for $\left.t \leq 9\right)$.

There were two sharp falls in the efficiency associated with the educational technology, one in the 1930s and another in the 1970s, after the Kenyan government had started to reform the school system yet again. The transmission factor $z_{t}$ fell by about $45 \%$ during the $1970 \mathrm{~s}$, and settled at a value just above $0.5,\left(z_{9} \in[0.53,0.61]\right.$ in all solutions $)$. With $z_{t}$ sharply reduced, the growth rate of $\lambda$ slows too; indeed, the young adults' level of efficiency falls between 1980 and 1990. The economy experiences another shock over the period $1990-2000$, as $\alpha_{t}$ falls by about 19\%. This shock has two effects: first, labor 
income is reduced. Second, raising children becomes relatively more expensive. Recalling (9), note that the costs incurred in raising children depend on $b, \lambda_{t+1}$ and $N_{t+1}^{1}$ only, ${ }^{16}$ and not on $\alpha_{t+1}$, which was constant during the years used in the calibration of $b$. As a consequence, the ratio $b / \alpha_{t}$ was constant too for $t=7$ and $t=9$. By 2000, however, the ratio rises as $\alpha_{t}$ falls, so that raising children is now relatively more expensive.

While the projections are computed for all 27 calibrations, we will present the results of one specific calibration in detail to illustrate the processes underway. The aggregate results of all other calibrations will also be set out. The parameters of the calibration chosen for a detailed description are set out in table 7 , while the average values of the parameters are reported in figure 1 and table 24 in the appendix. As can be seen from tables 7 and 24, the calibration chosen for detailed description is, to some extent, the 'average' calibration.

Table 7: Calibration Results

\begin{tabular}{|c|c|c|c|}
\hline \multicolumn{4}{|c|}{ Exogenous: } \\
\hline$A=0.10$ & $\epsilon=0.53$ & $\eta=1.46$ & \\
\hline \multicolumn{4}{|c|}{ Endogenous: } \\
\hline$\mu=0.538$ & $\chi=0.133$ & $b=273.94$ & \\
\hline$\beta_{0}=1.8801$ & $\beta_{1}=1.6132$ & $z_{t}$ & $\alpha_{t}$ \\
\hline \hline$t$ & $\lambda_{t}$ & 1.6791 & - \\
\hline 2 & 1.01 & 1.6791 & - \\
\hline 3 & 1.6688 & 1.0188 & 1357 \\
\hline 4 & 2.2192 & 1.0177 & 1357 \\
\hline 5 & 2.3917 & 1.0177 & 1357 \\
\hline 6 & 3.0183 & 1.0177 & 1357 \\
\hline 7 & 4.2922 & 0.5613 & 1104 \\
\hline 8 & 6.1094 & 0.5613 & \\
\hline 9 & 5.2868 & 0.5613 & \\
\hline 10 & 5.6710 & & \\
\hline
\end{tabular}

To summarize, the calibration is done in two steps: the first determines the parameters of the technologies and historical values of $\lambda$, while the second deals with the preference parameters. To derive the parameter values we have imposed two sets of restrictions:

\footnotetext{
${ }^{16}$ If the costs incurred in raising children were a function of $\alpha$, the factor describing labor productivity would drop out of the utility function, as this is logarithmic in form. As a consequence, all decisions on children would be independent of $\alpha$, which does not seem realistic.
} 
first $\mu \leq 1, \beta_{0} / \beta_{1} \leq 1.02^{20}$, with $\beta_{0} \geq \beta_{1}$, and $c_{1, t} / c_{2, t} \approx 1$, which have economic reasons and are independent of the data employed or the country/problem analyzed. The second set of restrictions imposed concerns $z_{t}$ and $\alpha_{t}$. These restrictions are specific to the data set used, and hence to the country/historical experience it reflects. Changing any of the restrictions will lead to significant changes in the calibration results, if any can be derived at all. Koukoumelis (2005) shows that the calibration will, in general, be sensitive to even small measurement errors in $Y_{5}$, the 1950 GDP level. He also shows that the degree of sensitivity to errors in $Y_{5}$ can be reduced by choosing a different set of restrictions regarding $z_{t}$. In the present paper, we have kept the original restriction in Bell et al. (2004) in order to ensure that the calibrations are comparable.

\section{Projections: The Base Case}

\subsection{Preliminaries}

Using the results of the calibrations presented in the previous section, the household decisions regarding completed fertility and education are determined under several scenarios. First, there is the benchmark case without HIV/AIDS, which is the counterfactual. Second, there the AIDS scenario in which the HIV/AIDS epidemic breaks out, and families fully recognize its effects during the 1990s, and adapt their earlier decisions about education accordingly (Scenario 1). We assume that fertility decisions have already been fully implemented by the time children are at school. Third, there is the case in which parents fail to take notice of the epidemic's effects until the late 1990s (Scenario 2). In all cases, the projections start with $N_{9}^{1}$ and $e_{9}$, that is, the first decisions are made in period $t=8$ and implemented/revised in period $t=9$.

\subsubsection{Data}

To compute the projections, data on mortality rates for 2000 onwards are needed. For both scenarios, revised projections based on those made by the US Bureau of Census are used, following Bell et al. (2004). The population pyramids for both cases are given in tables 8 and 9 . The implicit survival rates $\kappa_{t}$ and mortality rates $\left(1-\kappa_{t}\right)$ are set out in table 10. Survival rates for the second age group (age 15 to 24) are lower by up to 30 percentage points if the epidemic breaks out, and mortality rates are at least 1.9 times higher in the case of AIDS. At the peak of the epidemic, mortality rates are more than 3 times higher than their respective values in the case without AIDS during four consecutive decades. 
Table 8: Projections: Population Tables without AIDS

\begin{tabular}{|l|ccccccccc|}
\hline & 1990 & 2000 & 2010 & 2020 & 2030 & 2040 & 2050 & 2060 & 2070 \\
\hline $0-4$ & 4458 & 4696 & 4602 & 4503 & 4537 & 4398 & 4336 & 4336 & 4336 \\
$5-14$ & 7182 & 9006 & 9550 & 8995 & 8965 & 8968 & 8715 & 8715 & 8715 \\
$15-24$ & 4715 & 6875 & 8666 & 9236 & 8744 & 8759 & 8807 & 8601 & 8644 \\
$25-34$ & 2979 & 4447 & 6526 & 8277 & 8878 & 8458 & 8525 & 8624 & 8475 \\
$35-44$ & 1833 & 2731 & 4116 & 6098 & 7809 & 8454 & 8129 & 8269 & 8442 \\
$45-54$ & 1099 & 1634 & 2463 & 3755 & 5628 & 7290 & 7982 & 7761 & 7982 \\
$55-64$ & 698 & 911 & 1379 & 2115 & 3280 & 4998 & 6581 & 7323 & 7234 \\
$65+$ & 511 & 864 & 1294 & 1969 & 3131 & 5266 & 8395 & 8395 & 8395 \\
\hline
\end{tabular}

Source: Bell et al. (2004)

Table 9: Projections: Population Tables with AIDS

\begin{tabular}{|l|ccccccccc|}
\hline & 1990 & 2000 & 2010 & 2020 & 2030 & 2040 & 2050 & 2060 & 2070 \\
\hline $0-4$ & 4458 & 4556 & 3874 & 3436 & 3238 & 3038 & 2972 & 2972 & 2972 \\
$5-14$ & 7182 & 8612 & 8416 & 7197 & 6578 & 6258 & 5971 & 5971 & 5971 \\
$15-24$ & 4715 & 6839 & 8209 & 8040 & 6945 & 6429 & 6186 & 5902 & 5902 \\
$25-34$ & 2979 & 4187 & 5780 & 6912 & 6997 & 6360 & 6182 & 5948 & 5676 \\
$35-44$ & 1833 & 2410 & 3052 & 4136 & 5266 & 5873 & 5878 & 5713 & 5498 \\
$45-54$ & 1099 & 1487 & 1760 & 2173 & 3125 & 4372 & 5352 & 5357 & 5207 \\
$55-64$ & 698 & 906 & 1149 & 1361 & 1746 & 2666 & 3956 & 4843 & 4847 \\
$65+$ & 511 & 821 & 1087 & 1362 & 1693 & 2353 & 3657 & 3657 & 3657 \\
\hline
\end{tabular}

Source: Bell et al. (2004)

Table 10: Survival rates $\kappa_{t}$ and mortality rates $\left(1-\kappa_{t}\right)$ in the benchmark cases

\begin{tabular}{|lc|cccccc|}
\hline & & 1990 & 2000 & 2010 & 2020 & 2030 & 2040 \\
\hline NO AIDS & $\kappa_{t}$ & 0.827 & 0.844 & 0.862 & 0.881 & 0.899 & 0.918 \\
AIDS & $\kappa_{t}$ & 0.591 & 0.519 & 0.541 & 0.633 & 0.765 & 0.842 \\
\hline NO AIDS & $1-\kappa_{t}$ & 0.173 & 0.156 & 0.138 & 0.119 & 0.101 & 0.082 \\
AIDS & $1-\kappa_{t}$ & 0.409 & 0.481 & 0.459 & 0.367 & 0.235 & 0.158 \\
\hline
\end{tabular}

$\kappa_{t}$ is the probability that an adult in age group $a=3$ will survive 20 years, to reach age group $a=5$. 
$N_{t}^{1}$ is derived endogenously in the present model, in contrast to the projections in tables 8 and 9 . Yet the implicit survival probabilities underlying these tables are used to compute the number of adults in each age group in future periods, and therefore new age pyramids:

$$
N_{t+i}^{1+i}=N_{t}^{1} \cdot\left(1-q_{t}^{1,1+i}\right), \quad i \geq 1
$$

where $q_{t}^{1, i}$ is the probability that a member of age group 1 in period $t$ will not survive to become a member of age group $1+i$ in period $t+i$. Equation (17) enables the calculation of the diagonals of the population table, namely, values for $N_{t+1}^{2}, N_{t+2}^{3}, N_{t+3}^{4}, \ldots$, starting with $N_{t}^{1}$, which is endogenous. Those values of the age pyramid which cannot be computed using (17), for example $N_{9}^{2}$ or $N_{11}^{4}$, are taken from table 9.

One last step is necessary before turning to the projections, namely, the determination of $N_{\min }^{1}$ and $N_{\max }^{1}$. As the number of school-going children depends on the number of families, one must define $N_{\min }^{1}$ and $N_{\max }^{1}$ relative to family size. We choose $N_{\min }^{1}$ so as to allow stationarity with respect to population size. As some children and adults always die prematurely, even without an AIDS epidemic, the replacement fertility rate will lie somewhat above 1 . In the light of these data, $N_{\min }^{1}$ is set to

$$
N_{\min }^{1}=1.05 \cdot \frac{N_{t}^{2}+N_{t}^{3}}{2} \forall t
$$

in every period $t$. Variations in $N_{\min }^{1}$ will be discussed in section 6.1. It turns out that the value of $N_{\max }^{1}$ plays a minor role in all but one variation. Historically, the highest number of children raised $(a=1)$ per family according to the above definition was 1.91 during the 1980s. Therefore, we choose $N_{\text {max }}^{1}$ slightly higher, so that $2 N_{t}^{1} /\left(N_{t}^{2}+N_{t}^{3}\right) \leq 1.95$ or

$$
N_{\max }^{1}=1.95 \cdot \frac{N_{t}^{2}+N_{t}^{3}}{2} \forall t
$$

This implies that, in a steady state, the total population can double within about 20 years if all families choose $N_{t}^{1}=N_{\text {max }}^{1}$. We also assume that the number of children cannot drop from $N_{\max }^{1}$ to $N_{\min }^{1}$ within one period. If the family's optimum yields $2 N_{t}^{1} /\left(N_{t}^{2}+N_{t}^{3}\right)>$ $(1.95+1.05) / 2=1.5$ in some period $t$, then the minimum number of children in the following period, $t+1$, is set to $N_{\min }^{1}=\left[1.05 / 2+N_{t}^{1} /\left(N_{t}^{2}+N_{t}^{3}\right)\right] \cdot\left(N_{t+1}^{2}+N_{t+1}^{3}\right) / 2$ instead of $N_{\min }^{1}=1.05\left(N_{t+1}^{2}+N_{t+1}^{3}\right) / 2$. Only in period $t+2$ does $N_{\min }^{1}$ take the restricted value of $N_{\min }^{1}=1.05\left(N_{t+2}^{2}+N_{t+2}^{3}\right) / 2$. Consider, for example, $t=9$, where $2 N_{9}^{1} /\left(N_{9}^{2}+N_{9}^{3}\right)=$ $1.87>1.5$. This yields, in period $t=10: N_{\min }^{1}=[(1.05+1.87) / 2] \cdot\left(N_{10}^{2}+N_{10}^{3}\right) / 2=$ 
$1.46 \cdot\left(N_{10}^{2}+N_{10}^{3}\right) / 2$ instead of $N_{\min }^{1}=1.05 \cdot\left(N_{10}^{2}+N_{10}^{3}\right) / 2$, that is, $N_{\min }^{1}$ is higher by nearly $40 \%$.

\subsubsection{Procedure}

For each year, the solution to the household maximization problem, that is, the optimal values of $N_{t}^{1}$ and $e_{t}$, is computed. Both interior solutions, i.e. solutions to (14), and a total of 8 corner solutions are calculated in order to find the optimum, including interior solutions with respect to only one variable, that is, solutions in which $N_{t}^{1}$ is at the corner, while $e_{t}$ solves the corresponding first-order condition in (14), and vice versa. $\lambda_{t+1}$ and the relevant values of the age pyramid are calculated using (4) and (17), and these values are then used to determine the household optima for the following periods. The projections are limited to 2040 .

As noted before, Kenya abolished fees for primary education in 2003, which reduced the costs of schooling by about half. This reduction came surprisingly, as part of a campaign promise of a newly elected government, and it cannot be assumed that parents anticipated it during the 1990s, that is, when they made and implemented their fertility decisions. As a consequence, we will proceed as follows to determine the optimal levels of $e_{10}$ and $N_{10}^{1}$ : first, we determine $e_{10}$ and $N_{10}^{1}$ assuming that $\sigma_{10}=\sigma_{9}$. In a second step, we assume that parents observe the abolishment of school fees and revise their decision on $e_{10}$.

The following sections will discuss the results of the model simulations with the calibration in table 7 in detail. The summary of simulation outcomes with the other calibrations' results are reported in tables 25 to 29 in the appendix.

\subsection{The Benchmark Cases}

\subsubsection{The NO AIDS case}

The results for the first benchmark case, that is, the scenario without an HIV/AIDS epidemic, are set out in table 11.

The variable $y_{t}$ denotes GDP per capita, and is computed from the last two columns. Total population, measured in $1000 \mathrm{~s}$, is stated in the last column. With $N_{\min }^{1}=0.525\left(N_{t}^{2}+N_{t}^{3}\right)$, a value of 1.05 in the fourth column of the table indicates a corner solution with respect to $N_{t}^{1}$. Similarly, a value of 1.46 for $t=10$ also denotes a corner solution, as described in section 5.1.1. In the first benchmark case, parents reduce fertility during the 1990s 
Table 11: Benchmark Case: NO AIDS

\begin{tabular}{|l|cccccccc|}
\hline year $t$ & $\lambda_{t}$ & $N_{t}^{1}$ & $\frac{N_{t}^{1}}{\left(N_{t}^{2}+N_{t}^{3}\right) / 2}$ & $e_{t}$ & $y_{t}$ & $Y_{t}\left(10^{7}\right)$ & Pop. & $E_{t} U$ \\
\hline 9 & 5.29 & 7182 & 1.87 & 0.57 & 1310 & 3076 & 23475 & 26.47 \\
10 & 5.67 & 8256 & 1.46 & 0.93 & 1242 & 3730 & 30023 & 26.13 \\
11 & 6.97 & 8160 & 1.13 & 1.00 & 1530 & 5480 & 35814 & 26.44 \\
12 & 8.17 & 10216 & 1.32 & 1.00 & 1641 & 7341 & 44746 & 26.78 \\
13 & 9.51 & 12606 & 1.44 & 1.00 & 1787 & 9955 & 55701 & 27.56 \\
14 & 11.02 & 15217 & 1.39 & 1.00 & 2005 & 13791 & 68772 & 28.46 \\
\hline
\end{tabular}

sharply, from 1.87 children per family to 1.46 children a decade later. This has two reasons: first, as school fees are abolished, the costs of education are reduced by half, so that parents now increase education. Second, the productivity parameter $\alpha_{t}$ drops by $19 \%$, from its 1990 value of 1357 to 1104 in 2000. ${ }^{17}$ As a consequence, raising children is now relatively more expensive, the value of $b$ remaining unchanged, and parents must reduce $N_{t}^{1}$ in order to be able to finance child-raising. ${ }^{18}$ By 2010, all children start enjoying full-time schooling, and parents find it worthwhile to invest in having more children once again. As a consequence, $N_{t}^{1}, t \geq 11$ all lie above $N_{\min }^{1}$, while $e_{t}=1.0 \forall t \geq 11$.

\subsubsection{Scenario 1: Revision of $e_{9}$}

The HIV/AIDS epidemic does not (measurably) change the adult population structure for 1990, the first year of interest, as can be seen from tables 8 and 9. It does, however, change the parents' expectations, concerning both future mortality rates and population pyramids. Fewer of them will survive to old age, so that consumption in that phase of life becomes effectively less important than consumption while they are young, as the weight attached to $c_{2, t+2}, \beta_{1} \kappa_{t}$, falls. The interior solution is $N_{9}^{1}=4453$ and $e_{9}=0.70$, that is, parents would like to reduce fertility and increase schooling compared to the NO AIDS case, which, in turn would reduce income from child labor $(4453 \cdot(1-0.70)<$ $7182 \cdot(1-0.57))$. However, school-children in the 1990s have already been born, so that parents cannot choose $N_{9}^{1}$ as they wish. They can, however, revise their choice of $e_{9}$ downwards, which yields $e_{9}=0.42$. Total GDP in 1990 is slightly higher than in the NO AIDS case, due to the increase in child labor. After 1990, the level of schooling grows, albeit slowly. Child labor disappears by 2020, a full decade later that in the NO AIDS

\footnotetext{
${ }^{17}$ The fact that the size of the labor force has also increased reduces the labor productivity - and therefore increases the relative child-raising costs - by another $4 \%$.

${ }^{18}$ Note that this result would not hold if the child-raising costs were defined as $N_{t}^{1} b \lambda_{t} \cdot \alpha_{t} / \sum_{a=2}^{6} N_{t}^{a}$ rather than $N_{t}^{1} b \lambda_{t}$.
} 
case. In the first benchmark case, GDP grows, on average, by 3\% annually between 1990 and 2040, and by only $1.7 \%$ annually in the AIDS scenario. Total GDP in the NO AIDS case is higher by $90 \%$ than in the AIDS case for 2040. Population is always lower with the epidemic, by $40 \%$ in 2040 . It grows by $2.2 \%$ annually on average in the NO AIDS case over the period 1990 - 2040, and by only half that rate in the AIDS case. Compared to the US Bureau's projections in tables 8 and 9, total population in 2040 as predicted by the present model is higher by $22 \%$ in the NO AIDS case and by $11 \%$ in the AIDS case. Per capita GDP falls between 1990 and 2000 in the NO AIDS benchmark case, due to the

Table 12: Scenario 1: AIDS, Revision of $e_{9}$

\begin{tabular}{|l|cccccccc|}
\hline year $t$ & $\lambda_{t}$ & $N_{t}^{1}$ & $\frac{N_{t}^{1}}{\left(N_{t}^{2}+N_{t}^{3}\right) / 2}$ & $e_{t}$ & $y_{t}$ & $Y_{t}\left(10^{7}\right)$ & Pop. & $E_{t} U$ \\
\hline 9 & 5.29 & 7182 & 1.87 & 0.42 & 1324 & 3107 & 23475 & 23.35 \\
10 & 4.97 & 8040 & 1.46 & 0.57 & 1186 & 3434 & 28944 & 21.91 \\
11 & 5.26 & 7058 & 1.05 & 0.91 & 1352 & 4163 & 30799 & 22.17 \\
12 & 6.47 & 6928 & 1.05 & 1.00 & 1484 & 4817 & 32464 & 23.36 \\
13 & 7.60 & 7829 & 1.25 & 1.00 & 1583 & 5655 & 35717 & 25.33 \\
14 & 8.94 & 9186 & 1.33 & 1.00 & 1754 & 7268 & 41445 & 26.98 \\
\hline
\end{tabular}

drop in $\alpha_{t}$ in 2000. After this initial reduction of about 5\%, per capita GDP grows in all decades thereafter; however, the growth rate is low - only $1.2 \%$ annually, on average. In the AIDS case, $y_{t}$ is higher in 1990 compared to the NO AIDS case, by about 1\%. This is due to the fact that children work more. Per capita GDP falls between 1990 and 2000, and the drop is twice as large as in the NO AIDS case. $y_{t}$ grows slowly after 2010, and, by 2010, GDP per capita in the AIDS case is no greater than its level in the NO AIDS case. By 2040, per capita GDP in the AIDS case is $12 \%$ lower than it would have been if the epidemic had not broken out.

\subsubsection{Scenario 2: Delayed Expectations}

If households do not realize the outbreak of the epidemic until the late 1990s, they cannot revise their decisions about education, so that $e_{9}^{\text {Scenario } 2}=e_{9}^{\text {NOAIDS }}=0.57$. Consequently, $\lambda_{10}$ is higher than in Scenario $1(5.67>4.97)$, which has two effects: first, households can produce more, and are therefore richer. Second, education is more profitable, as $z_{10}\left(N_{10}^{2} \lambda_{10}+N_{10}^{3} \lambda_{9}\right) /\left(N_{10}^{2}+N_{10}^{3}\right)$ is higher. ${ }^{19}$ As a consequence, parents can now invest more in education, so that $e_{t}$ is somewhat higher in scenario 2 in all periods, and full-time

\footnotetext{
${ }^{19}$ Note that $N_{10}^{2}, N_{10}^{3}$ as well as $\lambda_{9}$ and $z_{10}$ are identical in both scenarios, so that the size of term above is determined by $\lambda_{10}$ alone.
} 
Table 13: Scenario 2: Delayed Expectations

\begin{tabular}{|l|cccccccc|}
\hline year $t$ & $\lambda_{t}$ & $N_{t}^{1}$ & $\frac{N_{t}^{1}}{\left(N_{t}^{2}+N_{t}^{3}\right) / 2}$ & $e_{t}$ & $y_{t}$ & $Y_{t}\left(10^{7}\right)$ & Pop. & $E_{t} U$ \\
\hline 9 & 5.29 & 7182 & 1.87 & 0.57 & 1310 & 3076 & 23475 & 26.47 \\
10 & 5.67 & 8040 & 1.46 & 0.59 & 1255 & 3634 & 28944 & 22.05 \\
11 & 5.69 & 7058 & 1.05 & 1.00 & 1446 & 4452 & 30799 & 22.38 \\
12 & 7.38 & 6928 & 1.05 & 1.00 & 1632 & 5299 & 32464 & 23.64 \\
13 & 8.35 & 8034 & 1.28 & 1.00 & 1735 & 6251 & 36023 & 25.65 \\
14 & 9.87 & 9400 & 1.35 & 1.00 & 1939 & 8135 & 41964 & 27.33 \\
\hline
\end{tabular}

schooling is attained earlier than in the first scenario. Parents being wealthier (higher $\lambda_{t}$ ), they can also invest more in fertility after 2020, that is, when mortality rates fall. All variables are higher in the second scenario compared to the first (Population by about $1 \%$, GDP by $12 \%$, and GDP per capita and human capital by $10 \%$ ), but still lower than in the NO AIDS case (Population by $39 \%$, GDP by $41 \%$, GDP per capita by $3 \%$, human capital by $10 \%)$.

Therefore, from both an individual ${ }^{20}$ and an aggregate point of view, scenario 2 yields better results, with a weaker impact of the epidemic, than the first scenario, in which parents revise their decisions about schooling during the 1990s.

\section{Variations: Parameters}

To test how sensitive the results derived above are to the assumptions made, some variations in the latter will now be presented. The variations will concern the choice of $N_{\min }^{1}$, and alternative paths for $\left\{\sigma_{t}\right\}_{t=9,10, \ldots},\left\{\alpha_{t}\right\}_{t=9,10, \ldots}$ and $\left\{z_{t}\right\}_{t=9,10, \ldots}$. In all variations, it will be assumed that parents perfectly foresee all future changes in parameters, even if they do not immediately foresee the course of the HIV/AIDS epidemic.

\subsection{Variation 1: The level of $N_{\min }^{1}$}

The first major assumption concerned the minimum number of children parents can choose to have, which was set by the condition $N_{\min }^{1}=1.05 \cdot\left(N_{t}^{2}+N_{t}^{3}\right) / 2$. As a variation, $N_{\min }^{1}$ is increased slightly, to $N_{\min }^{1}=1.1 \cdot\left(N_{t}^{2}+N_{t}^{3}\right) / 2$. The results can be found in table 14 . In the NO AIDS case, parents now raise more children than in the benchmark case in all

\footnotetext{
${ }^{20}$ The expected levels of utility are also higher in all periods in the second scenario compared to the first.
} 
Table 14: Variation 1: The level of $N_{\min }^{1}$

\begin{tabular}{|l|cccccccc|}
\hline \multicolumn{7}{|c|}{ NO AIDS } \\
\hline year $t$ & $\lambda_{t}$ & $N_{t}^{1}$ & $\frac{N_{t}^{1}}{\left(N_{t}^{2} N_{t}^{3}\right) / 2}$ & $e_{t}$ & $y_{t}$ & $Y_{t}\left(10^{7}\right)$ & Pop. & $E_{t} U$ \\
\hline 9 & 5.29 & 7182 & 1.87 & 0.57 & 1310 & 3076 & 23475 & 26.47 \\
10 & 5.67 & 8398 & 1.48 & 0.91 & 1235 & 3734 & 30239 & 26.13 \\
11 & 6.90 & 8274 & 1.13 & 1.00 & 1520 & 5492 & 36119 & 26.44 \\
12 & 8.13 & 10250 & 1.30 & 1.00 & 1637 & 7372 & 45038 & 26.76 \\
13 & 9.45 & 12699 & 1.44 & 1.00 & 1777 & 9970 & 56102 & 27.53 \\
14 & 10.96 & 15325 & 1.39 & 1.00 & 1994 & 13809 & 69272 & 28.44 \\
\hline \multicolumn{7}{|c|}{ AIDS, scenario 1: Revision of $e_{9}$} \\
\hline year $t$ & $\lambda_{t}$ & $N_{t}^{1}$ & $\frac{N_{t}^{1}}{\left(N_{t}^{2}+N_{t}^{3}\right) / 2}$ & $e_{t}$ & $y_{t}$ & $Y_{t}\left(10^{7}\right)$ & Pop. & $E_{t} U$ \\
\hline 9 & 5.29 & 7182 & 1.87 & 0.42 & 1324 & 3107 & 23475 & 23.35 \\
10 & 4.97 & 8178 & 1.48 & 0.56 & 1179 & 3437 & 29155 & 21.91 \\
11 & 5.21 & 7467 & 1.10 & 0.86 & 1327 & 4183 & 31527 & 22.16 \\
12 & 6.28 & 7533 & 1.10 & 1.00 & 1437 & 4864 & 33859 & 23.34 \\
13 & 7.48 & 8001 & 1.19 & 1.00 & 1574 & 5823 & 36982 & 25.29 \\
14 & 8.77 & 9444 & 1.30 & 1.00 & 1730 & 7418 & 42887 & 26.84 \\
\hline \multicolumn{7}{|c|}{ AIDS, scenario $2:$ Delayed Expectations } \\
\hline year $t$ & $\lambda_{t}$ & $N_{t}^{1}$ & $\frac{N_{t}^{1}}{\left(N_{t}^{2}+N_{t}^{3}\right) / 2}$ & $e_{t}$ & $y_{t}$ & $Y_{t}\left(10^{7}\right)$ & Pop. & $E_{t} U$ \\
\hline 9 & 5.29 & 7182 & 1.87 & 0.57 & 1310 & 3076 & 23475 & 26.47 \\
10 & 5.67 & 8178 & 1.48 & 0.58 & 1248 & 3638 & 29155 & 22.04 \\
11 & 5.63 & 7467 & 1.10 & 0.94 & 1418 & 4472 & 31527 & 22.37 \\
12 & 7.15 & 7533 & 1.10 & 1.00 & 1580 & 5349 & 33859 & 23.62 \\
13 & 8.21 & 8216 & 1.22 & 1.00 & 1724 & 6431 & 37302 & 25.61 \\
14 & 9.67 & 9671 & 1.32 & 1.00 & 1909 & 8292 & 43434 & 27.20 \\
\hline \multicolumn{70}{|c}{} \\
\hline
\end{tabular}


years but 1990, but they invest less in schooling; so that the level of efficiency of young adults is somewhat lower in all periods, as is per capita GDP. In 2000, parents choose the minimal level of fertility, and invest in education. By 2010, when children go to school full-time, parents start again to have more children. Total population and GDP are higher in all periods from 2000 onwards, but the difference is small, reaching $0.7 \%$ in 2040 . The difference in GDP is even smaller, amounting to less than $0.2 \%$.

In the first scenario, wherein parents reconsider their earlier decisions about $e_{9}$ when learning about HIV/AIDS, the new value for $e_{9}$ chosen remains unchanged, being independent of $N_{\min }^{1}$. Compared to the reference case, parents now have more, but worse-educated children until 2020 (see tables 13 and 14), and per capita GDP is lower in all periods. The impact of the epidemic on $\lambda_{t}$ and $y_{t}$ is stronger than in the case where the $N_{\min }^{1}-$ factor is 1.05, as parents can less afford to educate their more numerous children. Its impact on GDP and population, however, is weaker, as parents do not reduce fertility as much when the epidemic breaks out, so that population and GDP do not fall as sharply as in the reference case.

In the second scenario, that is, in the case of delayed expectations, GDP and population are higher than in the reference case (Table 13), as parents have more children from 2000 until 2010. They invest less in education, so that $e_{t}, \lambda_{t}$ and per capita GDP lie below their respective reference values. The effects of the epidemic on GDP and Population, however, are weaker than in the reference case.

\subsection{Variation 2: The level of $\sigma_{t}$}

The households' decisions on schooling are strongly influenced by the costs of education, $\sigma_{t}$, which were reduced during the 2000s as school fees were abolished. This led to an increase in education, which might have countervailed the effects of the HIV/AIDS epidemic. To disentangle the effects from these two shocks, we will now simulate the household's decisions if school fees had not been abolished. The results are reported in table 15 .

In all cases, it takes at least one decade longer to eradicate child labor. The effects are arguably strongest in the first scenario, in which child labor is still present in 2040. When the epidemic breaks out, parents now reduce education much more sharply than they did in the benchmark case: for example, $e_{10} \approx 0.38$ in both scenarios, compared to $e_{10} \approx 0.6$ in the reference cases, which means that children work $50 \%$ more. The effects of the epidemic on human capital and GDP per capita are therefore stronger than in the 
reference case. For example, in the first scenario, 2040 human capital is lower by about $19 \%$ than in the NO AIDS case if school fees are ablosihed, and by $43 \%$ if they are not. With schooling being more expensive, parents now prefer to invest in having more children when mortality rates are high. Consequently, population size is higher than in the respective reference cases from 2010 onwards, while the effects of the epidemic on total population are somewhat weaker (see tables 25 and 27).

The reduction of schooling costs contributed strongly to mitigating the effects of the epidemic on all measures but population. Note, however, than an underlying assumption is that, while school fees were abolished, school quality (i.e. $z_{t}$ ) remains unchanged. Schools have to instruct many more pupils,$^{21}$ and loose one important source of funding. Governmental spending on primary education as a share of GDP did not change much either - it actually fell from $7.17 \%$ in 2002 to $6.98 \%$ in $2003 .{ }^{22}$ Measured in local currency units, however, public spending on primary education rose sharply from 3322 Million Khs in 2002/2003 to 5967 Million Khs in 2003/2004 - a rise of nearly $80 \%{ }^{23}$ To sum up, the assumption that quality of education was unaffected by the abolition of school fees might not hold, and one could expect $z_{t}$ to have been lower than its calibrated value at least temporatily. However, no data are available allowing us to recalibrate $z_{t}$, and the change in the pupil/teacher-ratio as one measure of school quality suggest that it did not change much.

\subsection{Variation 3: The level of $\alpha_{t}$}

The labor productivity factor $\alpha_{t}$ dropped by $19 \%$ in the decade following 1990, from 1357 to 1104, and this reduction is the main reason for the households' decision to reduce fertility from 2000 onwards, even in the absence of the disease - see section 5.2. Assume that $\alpha_{t}$ recovers after the sharp drop in the 1990s, to some value between $\alpha_{10}$ and $\alpha_{9}$. To be precise, let productivity take the value $\alpha_{t}=0.5\left(\alpha_{9}+\alpha_{10}\right)$ after 2000. As in the previous section, it will be assumed that parents foresee changes in $\alpha_{t}$ perfectly. The results are set out in table 16 .

\footnotetext{
${ }^{21}$ According to World Bank Data (WDI 2006), the number of children enrolled in primary education increased by 900000 , or $18 \%$, between 2002 and 2003, while the number of teachers increased by $7 \%$. This implies that each teacher had to tutor about 3.5 additional students, on average.

${ }^{22}$ Source: Worldbank, WDI 2006

${ }^{23}$ Source: Kenya Ministry of Education, http://www.education.go.ke/Statistics/EducationExpenditure.pdf, as of Sept. 22, 2006. The data in the text refers to 'recurring costs'. If development costs are inluded, the rise amounts to nearly $190 \%$.
} 
Table 15: Variation 2: The level of $\sigma_{t}$

\begin{tabular}{|c|c|c|c|c|c|c|c|c|}
\hline \multicolumn{9}{|c|}{ NO AIDS } \\
\hline year $t$ & $\lambda_{t}$ & $N_{t}^{1}$ & $\frac{N_{t}^{1}}{\left(N_{t}^{2}+N_{t}^{3}\right) / 2}$ & $e_{t}$ & $y_{t}$ & $Y_{t}\left(10^{7}\right)$ & Pop. & $E_{t} U$ \\
\hline 9 & 5.29 & 7182 & 1.87 & 0.57 & 1310 & 3076 & 23475 & 26.47 \\
\hline 10 & 5.67 & 8256 & 1.46 & 0.59 & 1263 & 3793 & 30023 & 26.03 \\
\hline 11 & 5.69 & 8662 & 1.20 & 0.88 & 1393 & 5091 & 36559 & 26.05 \\
\hline 12 & 6.96 & 9413 & 1.18 & 1.00 & 1522 & 6701 & 44027 & 26.34 \\
\hline 13 & 8.14 & 11294 & 1.31 & 1.00 & 1610 & 8600 & 53410 & 26.91 \\
\hline 14 & 9.52 & 13317 & 1.34 & 1.00 & 1769 & 11386 & 64347 & 27.83 \\
\hline \multicolumn{9}{|c|}{ AIDS, scenario 1: Revision of $e_{9}$} \\
\hline year $t$ & $\lambda_{t}$ & $N_{t}^{1}$ & $\frac{N_{t}^{1}}{\left(N_{t}^{2}+N_{t}^{3}\right) / 2}$ & $e_{t}$ & $y_{t}$ & $Y_{t}\left(10^{7}\right)$ & Pop. & $E_{t} U$ \\
\hline 9 & 5.29 & 7182 & 1.87 & 0.42 & 1324 & 3107 & 23475 & 23.35 \\
\hline 10 & 4.97 & 8040 & 1.46 & 0.37 & 1199 & 3471 & 28944 & 21.85 \\
\hline 11 & 4.37 & 7058 & 1.05 & 0.54 & 1279 & 3939 & 30799 & 21.91 \\
\hline 12 & 4.74 & 7597 & 1.15 & 0.62 & 1245 & 4166 & 33453 & 22.79 \\
\hline 13 & 4.98 & 9331 & 1.41 & 0.67 & 1176 & 4540 & 38604 & 24.42 \\
\hline 14 & 5.41 & 10056 & 1.27 & 0.81 & 1226 & 5494 & 44798 & 25.67 \\
\hline \multicolumn{9}{|c|}{ AIDS, scenario 2: Delayed Expectations } \\
\hline year $t$ & $\lambda_{t}$ & $N_{t}^{1}$ & $\frac{N_{t}^{1}}{\left(N_{t}^{2}+N_{t}^{3}\right) / 2}$ & $e_{t}$ & $y_{t}$ & $Y_{t}\left(10^{7}\right)$ & Pop. & $E_{t} U$ \\
\hline 9 & 5.29 & 7182 & 1.87 & 0.57 & 1310 & 3076 & 23475 & 26.47 \\
\hline 10 & 5.67 & 8040 & 1.46 & 0.38 & 1269 & 3673 & 28944 & 21.98 \\
\hline 11 & 4.70 & 7058 & 1.05 & 0.59 & 1365 & 4204 & 30799 & 22.11 \\
\hline 12 & 5.35 & 6928 & 1.05 & 0.74 & 1392 & 4520 & 32464 & 23.05 \\
\hline 13 & 5.83 & 8281 & 1.32 & 0.85 & 1351 & 4916 & 36392 & 24.75 \\
\hline 14 & 6.77 & 8781 & 1.24 & 1.00 & 1464 & 6043 & 41285 & 26.23 \\
\hline
\end{tabular}


In the NO AIDS case in 2000, parents would like most to have very few children (as raising them is relatively costly when $\alpha_{t}$ is low) but to educate these children very well, as future pay-offs from schooling are higher, with $\alpha_{t}$ expected to rise after 2000. However, due to the social rule on $N_{\min }^{1}$ each family in 2000 must raise at least 1.46 children, and therefore cannot afford to educate much them above $e_{10}^{\text {base case }}=0.93$. Thus, the changes in $\alpha_{t}$ do not lead to an increase in either $N_{10}^{1}$ or $e_{10}$, as one might expect. By 2010, however, when $\alpha_{t}$ has recovered substantially, the relative costs incurred in raising children are lower, and parents have more children than in the case of a low level of $\alpha_{t}$ for $t>10$. In all periods following 2010, both total and per capita GDP values are higher than in the benchmark case as $\alpha_{t}$ is higher.

Human capital levels are equal until at least 2010, and the levels in the variation exceed the levels in the benchmark case after that. Recall that the productivity of education depends on the teachers' 'parents' average level of human capital, $\left(N_{t}^{2} \lambda_{t}+N_{t}^{3} \lambda_{t}\right) /\left(N_{t}^{2}+N_{t}^{3}\right)$. If there are relatively more young (well-educated) adults in age group $a=2$, then the term above will grow, and education will be relatively more productive. Therefore, if parents have more children, and if these children enjoy the same education in both the variation and the benchmark case, the level of human capital of individuals leaving school 2 decades later will be higher. In the present case, $N_{11}^{1}=9996$ in the variation and $N_{11}^{1}=7058$ in the benchmark case. These children finish schooling by 2020, when they become parents themselves, and start teaching $N_{12}^{1}$. This cohort, in turn, finishes school by 2030, and their level of human capital is higher in the variation than in the benchmark case 9.58 $>9.51$. This effect can also be observed in the second scenario for $\lambda_{14}$.

As a consequence of the increased investment in fertility, total population is now much higher than in all other cases reported, and exceeds the 2040 values projected by the US Bureau of the Census by about 50\% and, respectively, 30\% in the NO AIDS and AIDS cases. The effects of the epidemic are somewhat stronger than in the benchmark case (see tables 25 and 28), with the differences amounting to max. 4 percentage points.

\subsection{Variation 3: The level of $z_{t}$}

As the adults' choice of $e_{t}$ is driven, at least in part, by $z_{t}$, the last variation presented will address the development of the transmission factor after 2000. Assume that $z_{t}$ recovers after 1990, and, following Bell et al. (2004), set its value to $z_{t}=0.65 \forall t \geq 10$. If parents perfectly foresee this change in the productivity of education, they will raise the level of 
Table 16: Variation 3: Recovery of $\alpha_{t}$ after 2000

\begin{tabular}{|l|cccccccc|}
\hline \multicolumn{7}{|c|}{ NO AIDS } \\
\hline year $t$ & $\lambda_{t}$ & $N_{t}^{1}$ & $\frac{N_{t}^{1}}{\left(N_{t}^{2}+N_{t}^{3}\right) / 2}$ & $e_{t}$ & $y_{t}$ & $Y_{t}\left(10^{7}\right)$ & Pop. & $E_{t} U$ \\
\hline 9 & 5.29 & 7182 & 1.87 & 0.57 & 1310 & 3076 & 23475 & 26.61 \\
10 & 5.67 & 8256 & 1.46 & 0.93 & 1242 & 3730 & 30023 & 26.28 \\
11 & 6.97 & 9996 & 1.38 & 1.00 & 1585 & 6107 & 38535 & 26.91 \\
12 & 8.17 & 13000 & 1.51 & 1.00 & 1729 & 8768 & 50701 & 27.46 \\
13 & 9.58 & 16327 & 1.49 & 1.00 & 1932 & 12695 & 65718 & 28.13 \\
14 & 11.08 & 20878 & 1.48 & 1.00 & 2168 & 18446 & 85089 & 28.74 \\
\hline \multicolumn{7}{|c|}{ AIDS, scenario 1: Revision of $e_{9}$} \\
\hline year $t$ & $\lambda_{t}$ & $N_{t}^{1}$ & $\frac{N_{t}^{1}}{\left(N_{t}^{2}+N_{t}^{3}\right) / 2}$ & $e_{t}$ & $y_{t}$ & $Y_{t}\left(10^{7}\right)$ & Pop. & $E_{t} U$ \\
\hline 9 & 5.29 & 7182 & 1.87 & 0.42 & 1324 & 3107 & 23475 & 23.45 \\
10 & 4.97 & 8040 & 1.46 & 0.57 & 1186 & 3434 & 28944 & 22.00 \\
11 & 5.26 & 7058 & 1.05 & 1.00 & 1501 & 4623 & 30799 & 22.55 \\
12 & 6.76 & 7555 & 1.15 & 1.00 & 1634 & 5457 & 33390 & 23.82 \\
13 & 7.77 & 9785 & 1.49 & 1.00 & 1688 & 6624 & 39241 & 25.92 \\
14 & 9.21 & 11788 & 1.45 & 1.00 & 1925 & 9196 & 47777 & 27.51 \\
\hline \multicolumn{7}{|c|}{ AIDS, scenario $2:$ Delayed Expectations } \\
\hline year $t$ & $\lambda_{t}$ & $N_{t}^{1}$ & $\frac{N_{t}^{1}}{\left(N_{t}^{2}+N_{t}^{3}\right) / 2}$ & $e_{t}$ & $y_{t}$ & $Y_{t}\left(10^{7}\right)$ & Pop. & $E_{t} U$ \\
\hline 9 & 5.29 & 7182 & 1.87 & 0.57 & 1310 & 3076 & 23475 & 26.61 \\
10 & 5.67 & 8040 & 1.46 & 0.59 & 1255 & 3634 & 28944 & 22.14 \\
11 & 5.69 & 7058 & 1.05 & 1.00 & 1611 & 4962 & 30799 & 22.76 \\
12 & 7.38 & 7508 & 1.14 & 1.00 & 1772 & 5905 & 33320 & 24.05 \\
13 & 8.35 & 9992 & 1.52 & 1.00 & 1812 & 7160 & 39504 & 26.17 \\
14 & 9.89 & 12102 & 1.48 & 1.00 & 2069 & 10017 & 48404 & 27.80 \\
\hline
\end{tabular}


schooling children enjoy during the 1990s, even though $z_{9}$ takes a low value; for young adults take into account the education of several future generations when making their decisions, and investing in $e_{t}$ early is profitable. Therefore, if there is perfect foresight concerning $z_{t}$, the results for 1990 will differ from the data. This issue can be solved by assuming either that $z_{t}$ recovers only later, that is, by 2010, or that parents do not take note of the changes in $z_{t}$ until they actually take place. To keep matters simple, assume that $z_{t}$ recovers only late, in 2010, that is: $z_{9}=z_{10}$ and $z_{t \geq 11}=0.65$.

Table 17: Variation 4: Recovery of $z_{t}$ by 2010

\begin{tabular}{|c|c|c|c|c|c|c|c|c|}
\hline \multicolumn{9}{|c|}{ NO AIDS } \\
\hline year $t$ & $\lambda_{t}$ & $N_{t}^{1}$ & $\frac{N_{t}^{1}}{\left(N_{t}^{2}+N_{t}^{3}\right) / 2}$ & $e_{t}$ & $y_{t}$ & $Y_{t}\left(10^{7}\right)$ & Pop. & $E_{t} U$ \\
\hline 9 & 5.29 & 7182 & 1.87 & 0.57 & 1310 & 3076 & 23475 & 26.47 \\
\hline 10 & 5.67 & 8256 & 1.46 & 0.95 & 1242 & 3727 & 30023 & 26.20 \\
\hline 11 & 7.02 & 8606 & 1.19 & 1.00 & 1506 & 5495 & 36475 & 26.61 \\
\hline 12 & 9.33 & 9532 & 1.20 & 1.00 & 1782 & 7869 & 44152 & 27.11 \\
\hline 13 & 11.70 & 11345 & 1.31 & 1.00 & 2057 & 11015 & 53551 & 27.96 \\
\hline 14 & 14.78 & 13329 & 1.33 & 1.00 & 2468 & 15913 & 64479 & 29.16 \\
\hline \multicolumn{9}{|c|}{ AIDS, scenario 1: Revision of $e_{9}$} \\
\hline year $t$ & $\lambda_{t}$ & $N_{t}^{1}$ & $\frac{N_{t}^{1}}{\left(N_{t}^{2}+N_{t}^{3}\right) / 2}$ & $e_{t}$ & $y_{t}$ & $Y_{t}\left(10^{7}\right)$ & Pop. & $E_{t} U$ \\
\hline 9 & 5.29 & 7182 & 1.87 & 0.42 & 1324 & 3107 & 23475 & 23.35 \\
\hline 10 & 4.97 & 8040 & 1.46 & 0.58 & 1186 & 3433 & 28944 & 21.96 \\
\hline 11 & 5.29 & 7058 & 1.05 & 1.00 & 1350 & 4158 & 30799 & 22.27 \\
\hline 12 & 7.70 & 6928 & 1.05 & 1.00 & 1590 & 5162 & 32464 & 23.64 \\
\hline 13 & 9.48 & 7266 & 1.16 & 1.00 & 1853 & 6461 & 34876 & 25.86 \\
\hline 14 & 12.24 & 8121 & 1.23 & 1.00 & 2222 & 8735 & 39313 & 27.72 \\
\hline \multicolumn{9}{|c|}{ AIDS, scenario 2: Delayed Expectations } \\
\hline year $t$ & $\lambda_{t}$ & $N_{t}^{1}$ & $\frac{N_{t}^{1}}{\left(N_{t}^{2}+N_{t}^{3}\right) / 2}$ & $e_{t}$ & $y_{t}$ & $Y_{t}\left(10^{7}\right)$ & Pop. & $E_{t} U$ \\
\hline 9 & 5.29 & 7182 & 1.87 & 0.57 & 1310 & 3076 & 23475 & 26.47 \\
\hline 10 & 5.67 & 8040 & 1.46 & 0.60 & 1255 & 3633 & 28944 & 22.10 \\
\hline 11 & 5.72 & 7058 & 1.05 & 1.00 & 1449 & 4462 & 30799 & 22.48 \\
\hline 12 & 8.41 & 6928 & 1.05 & 1.00 & 1722 & 5592 & 32464 & 23.87 \\
\hline 13 & 10.22 & 7402 & 1.18 & 1.00 & 1998 & 7010 & 35080 & 26.12 \\
\hline 14 & 13.19 & 8303 & 1.24 & 1.00 & 2403 & 9543 & 39717 & 28.00 \\
\hline
\end{tabular}

By construction, the results for 1990 remain unchanged compared to the benchmark cases, as $z_{11}$ does not appear in the household's maximization problem when it chooses $N_{9}^{1}$ and 
$e_{9}$. By 2000, however, parents start taking into account future changes in $z_{t}$, and increase education accordingly. Consequently, the adult level of efficiency in 2040 is higher by $34 \%$, while per capita and total GDP are higher by $23 \%$ and $15 \%$, respectively compared to the benchmark NO AIDS case.

As expected, the effects of the HIV/AIDS epidemic are slightly weaker than in the case where $z_{t}$ does not change, as parents invest heavily in education even in the presence of the epidemic. Despite the outbreak of the disease, per capita GDP in 2040 when $z_{t \geq 11}=0.65$ is higher than in the NO AIDS benchmark case (see table 11), and the difference amounts to about 10-20\%. Child labor is now eradicated by 2010 even if parents revise their earlier decisions about $e_{9}$.

\section{$7 \quad$ Policy}

Governmental intervention has been necessary, since the outbreak of the HIV/AIDS epidemic in Africa in the 1980s, particularly in the health and education sectors, in order to mitigate its adverse effects. Individuals in developing countries do not have the resources to learn unaided about how the disease is transmitted, and cannot afford the treatment if they become infected. With the number of AIDS orphans estimated to have risen by $30 \%$ between 2001 and 2003 alone, ${ }^{24}$ communities which have taken in orphans in the past are increasingly overwhelmed.

Governmental programs can therefore be classified into three types of measures: preventing the disease from spreading, treating and caring for the ill, and looking after orphans. Preventive measures encompass information campaigns in the media and schools, the distribution of condoms and setting up AIDS test facilities in all affected regions. Before the epidemic breaks out fully, the number of HIV infections typically rises in certain population groups like prostitutes and truck drivers - targeting preventive campaigns at these groups can prove to be highly effective.

After the epidemic breaks out, however, the economy must bear the combined burden of a workforce reduced by illness and death, and the costs of caring for the sick and their families. At this stage, public policies aim at extending the life of the infected through treatment and preventing them from spreading the disease to the healthy. While information campaigns in the media and schools remain important, measures now also consist of

\footnotetext{
${ }^{24}$ Source: 'Report on the global AIDS epidemic 2004,' U.N.AIDS, 2004, Page 193
} 
treating HIV-positive pregnant women with drugs to reduce the likelihood of the unborn child also being infected at delivery. With a prevalence rate among Kenyan adults aged $15-49$ of $6.7 \%$ in $2003,{ }^{25}$ that is, more than 1 million AIDS cases to follow, the medical infrastracture needs to be extended, by building additional hospitals and clinics, as well as training and employing more health personnel.

Preventive measures such as information campaigns and condom distribution are relatively cheap - particularly so before a full outbreak of the epidemic, when it is often sufficient to target focus groups. Marseille, Hofmann and Kahn (2002) estimate the costs of prevention at about 8-12 US\$ per case averted. Saving one disability-adjusted-life-year (DALY) through a bundle of measures such as prevention of mother-to-child transmission, supply of condoms for sex workers, control of sexually-transmitted diseases, voluntary counseling and testing as well as blood supply safety, costs an estimated US\$12.50. Treatment costs, for example through highly active antiretroviral therapy (HAART) are much higher: in the developed world, they exceed 10,000 US\$ per patient per year. With the emergence of generic drugs, which are intended for distribution in developing countries only, drug costs amount to 350 US $\$$ per patient per year. Note, however, that these costs do not include distributing the drugs and payments for medical personnel. As a consequence, Marseille, Hofmann and Kahn estimate the costs of saving a DALY for a cost-effective HAART program to be 395 US\$ per patient yearly.

\subsection{Procedure}

Intervention in the health sector will aim at reducing mortality rates, both through preventing AIDS from spreading and by treating those who are already ill. In the initial phase of the epidemic, intervention will consist mainly of cost-effective preventive measures. Treatment will gain importance when preventive measures do not bear fruit any more. Denote public spending on health in period $t$, normalized per sub-family, by $G_{t}$, and mortality rates in the presence of the disease $(D=1)$ by $q_{t}(D=1)$. Following Bell et al. (2004), assume the relationship between premature adult mortality in the presence of the disease and public spending on health to be as follows:

$$
1-\kappa_{t}\left(G_{t} ; D=1\right) \equiv q_{t}\left(G_{t} ; D=1\right)=d_{t}-\frac{1}{a_{t}+c_{t} e^{-b_{t} G_{t}}},
$$

which allows for sufficient curvature (diminishing returns) over a flexible interval. The values of $a_{t}, b_{t}, c_{t}$ and $d_{t}$ need to be calibrated for each period in which $G_{t}>0$. As the

\footnotetext{
${ }^{25}$ Source: 'Report on the global AIDS epidemic 2004,' U.N.AIDS, 2004, Page 191
} 
present essay uses the same data as Bell et al. (2004), the results derived there remain valid for present purposes. ${ }^{26}$ Due to the changes in mortality rates, the population tables

Table 18: The parameter values of the function $q_{t}\left(G_{t} ; D=1\right)$

\begin{tabular}{|c|c|c|c|}
\hline & 2000 & 2010 & 2020 \\
\hline$a_{t}$ & 0.9073 & 0.9863 & 1.3852 \\
$b_{t}$ & 0.0169 & 0.0187 & 0.0266 \\
$c_{t}$ & 0.3124 & 0.3395 & 0.4768 \\
$d_{t}$ & 1.2152 & 1.1128 & 0.8066 \\
\hline
\end{tabular}

Source: Bell et al. (2004)

need to be recalculated using (18) and table 18. To be able to compute the new values of $N_{t}^{a}$, the public spending program needs to be defined and the age-specific mortality rates $q_{t}^{a, a+1}$, must be formulated as a function of $q_{t}\left(G_{t} ; D=1\right)$. For reasons of comparability, the same functional form as in Bell et al. (2004) is chosen. Following Bell et al. (2004), $G_{t}$, i.e. the level of spending per family, is defined as:

$$
G_{t} \equiv \frac{P_{t}}{\left(N_{t}^{2}+N_{t}^{3}+N_{t}^{4}\right) / 2},
$$

with $P_{t}$ being the level of governmental spending on health. Consider the 30-year spending program:

$$
\mathbf{P}=\left(P_{2000}, P_{2010}, P_{2020}\right)=\left(50 \cdot 10^{6}, 100 \cdot 10^{6}, 100 \cdot 10^{6}\right),
$$

where $P_{2000}=50 \cdot 10^{6}$ means that 50 million dollars are spent on health every year between 2000 and 2009, and $P_{2010}$ and $P_{2020}$ can be interpreted analogously. Assume that the program $\mathbf{P}$ is financed through grants from abroad, which are fully funded by international donors. As the grants do not need to be repaid, levying taxes or reshuffling the governmental budget to finance them is not necessary. It is also assumed that the government has no means to extend the program beyond the donors' grants.

The age-specific mortality rates are then defined as follows:

$$
q_{t}^{a, a+1}\left(G_{t} ; D=1\right)=q_{t}^{a, a+1} \cdot\left(1-\frac{q_{t}\left(G_{t} ; D=1\right)}{q_{t}(0 ; D=1)}\right)
$$

As a consequence of the policy program $\mathbf{P}$, the number of children raised by a family and surviving to old age will now change, and the size of $G_{t}$ is endogenous because as

\footnotetext{
${ }^{26}$ Source: Bell et al. (2004), page 47
} 
$N_{t}^{a}$ is endogenous. Therefore, the population tables need to be recomputed in each period.

Parental decisions are determined in part by their expectations about future mortality rates. In the absence of public spending, parents were assumed to have perfect foresight about mortality rates. To keep matters simple in the case of governmental spending on health, assume parents are more short-sighted: They are aware of the mortality structure if the governmental spending did not take place, and of all future effects of the spending program. However, they do not take into account the effects their own decisions on $N_{t}^{1}$ will have on future values of $G_{t}$. Hence, the subjective estimates of $\kappa_{t}$ and $\kappa_{t+1}$ are computed as follows: The current population tables and mortality rates are taken as a basis to calculate $G_{t}$ from (19) and the new mortality rates $q_{t}^{a, a+1}\left(G_{t} ; D=1\right)$, from (18) and (20), which, in turn, are used to compute new values for $N_{t}^{a}$ from (17) and hence $\kappa_{t}$ and $\kappa_{t+1}$. All values of $N_{t}^{a}$ which are not influenced by the policy program $\mathbf{P}$ are left unchanged.

\subsection{Policy: Results}

As the policy program $\mathbf{P}$ does not affect the NO AIDS case, only the results for the AIDS scenarios are reported. Taking into account the history of policies to deal with AIDS in Kenya, it seems unlikely that households in the 1990s could have foreseen that a program would be implemented in the 2000s. Due to the nature of HIV/AIDS, the effects of such a program on mortality will not make themselves felt immediately, so that it will be assumed that, first, parents during the 1990s do not foresee the program, and second, that even during the 2000s they do not realize its effects, and therefore do not revise their decisions about $e_{10}$. Young adults in $t=10$, however, who decide about $N_{11}^{1}$ and $e_{11}$, realize the programs' effects and make their decisions accordingly. Therefore, even if the government intervenes in the health sector, the outcomes for $t=9$ and $t=10$ regarding fertility and schooling will remain unchanged. The results are set out in tables 30 to 34 in the appendix. The direct effects of the policy program on the families' decisions can be observed for 2010, that is, the first year in which they react to changes in mortality. Table 19 sets out the adult's level of efficiency in 2010 as well as the qualitative changes in fertility and education: a " + " in the third column states that fertility is higher compared to the case without public spending, a "--" denotes that fertility is lower, and a "0" means that it remains unchanged. The symbols in the last column are interpreted analogously.

As a consequence of the policy program $\mathbf{P}$, mortality rates are reduced, so that more 
Table 19: The effects of the policy program $\mathbf{P}$ on fertility and education: 2010

\begin{tabular}{|c|c|c|c|}
\hline & $\lambda_{t}$ & $\frac{N_{t}^{1}}{\left(N_{t}^{2}+N_{t}^{3}\right) / 2}$ & $e_{t}$ \\
\hline \multicolumn{4}{|l|}{ Base Case } \\
\hline Scenario 1 & 5.26 & 0 & + \\
\hline Scenario 2 & 5.69 & 0 & 0 \\
\hline \multicolumn{4}{|l|}{ Variation $1\left(N_{\min }^{1}\right)$} \\
\hline Scenario 1 & 5.21 & 0 & + \\
\hline Scenario 2 & 5.63 & 0 & + \\
\hline \multicolumn{4}{|l|}{ Variation $2\left(\sigma_{t \geq 10}\right)$} \\
\hline Scenario 1 & 4.37 & 0 & + \\
\hline Scenario 2 & 4.70 & 0 & + \\
\hline \multicolumn{4}{|l|}{ Variation $3\left(\alpha_{t \geq 10}\right)$} \\
\hline Scenario 1 & 5.26 & + & 0 \\
\hline Scenario 2 & 5.69 & + & 0 \\
\hline \multicolumn{4}{|l|}{ Variation $4\left(z_{t \geq 11}\right)$} \\
\hline Scenario 1 & 5.29 & 0 & 0 \\
\hline Scenario 2 & 5.72 & 0 & 0 \\
\hline
\end{tabular}

Scenario 1: $e_{9}$ subject to a binding contract

Scenario 2: $e_{9}$ revised by the first group

of the parents will survive to old age. At the same time, more of their children will survive to adulthood and be able to finance their parents in old age. Therefore, consumption in the second stage of adulthood becomes more important in all calculations. To finance it, parents can invest either in education, or in fertility, or in both. Recall that, in most variations and scenarios, parents already choose full-time schooling by 2010. In all cases in which $e_{11}^{G=0}<1$, parents increase schooling when the policy program is undertaken. Fertility is increased in one case only, namley, if $\alpha_{t}$ recovers, which also implies a reduction of the relative child-raising costs. The overall effects of the program on $\lambda_{t}, y_{t}, Y_{t}$ and population will be discussed in detail in section 9 .

\section{The Effects on Social Welfare}

In order to assess the overall effects of the epidemic and the policy program $\mathbf{P}$, a social welfare function (SWF) is required. The choice of a SWF, however, poses difficulties of its own. It has to capture and value several effects of the epidemic: first, some individuals die prematurely, and are robbed of the opportunity to enjoy their lives and be productive. 
Second, some individuals are never born, either because their parents die prematurely or because their parents decide to have fewer children. Third, even those individuals who do not die prematurely often enjoy less schooling than they would have done in the absence of the disease, so that their lifetime income is reduced and their parents' utility from the capacity they attain as adults will fall. There is very little literature on the evolution of welfare when fertility is endogenous. Schweizer (1996) considers an open economy and defines efficiency using the concept of net trade. His welfare measure, however, holds only for economies in a steady state, where population growth is constant over time. As this is not the case in our projections, the measure developed by Schweizer cannot be employed in our framework.

The first step is to decide what unit - monetary or physical - to use. As one of the reasons for introducing a social welfare function is to assess the effects and profitability of the policy program $\mathbf{P}$, and as the costs of this program are measured in dollars, we will choose a money-metric measure. In general, changes to an individual's level of utility are valued using the concepts of the compensating or equivalent variation ( $\mathrm{CV}$ and $\mathrm{EV})$, as these capture all individual-level effects described above and assign them a monetary value. The CV measures how much money, in the form of a lumpsum transfer, is required such that and individual's level of utility in the AIDS case with the lump-sum transfer be identical to her level of utility in the NO AIDS case: $U(N O A I D S ; \cdot)=U(A I D S, C V>0 ; \cdot)$. The EV is the lump-sum an individual is willing to pay in order to avoid the changes in mortality brought about by the HIV/AIDS epidemic and its consequences: $U(N O A I D S, E V<0 ; \cdot)=U(A I D S ; \cdot)$. The $\mathrm{CV}$ and $\mathrm{EV}$ measure the effects on individuals. By summing the $\mathrm{CV}$ and $\mathrm{EV}$ over all relevant individuals ${ }^{27}$ in some periods, it is possible to assess the overall losses and gains due to the epidemic or an intervention. This aggregation, however, does not include those individuals who are never born, but would have been under other circumstances. The CV and $\mathrm{EV}$ can be defined in an analogous way to compute the effects of the policy intervention.

The transfer can be paid or received either in period $t$, that is, while the children are going to school, or in period $t+2$, that is, when the parents reach old age, or in both periods. Note, first, that even though the transfers are lump-sum in form, parents will change $N_{t}^{1}$ and/or $e_{t}$. Consider, for example, a family receiving a lump-sum transfer $T_{t}$ in

\footnotetext{
${ }^{27}$ Aggregating the $E V^{h}$ over all individuals $h$ rests on the assumption that the marginal utility of income is the same for all individuals. This assumption is easily satisfied within a period, as all individuals are identical. However, the marginal utility of income will be identical between two periods by pure chance only.
} 
period $t$, and nothing in period $t+2$. As there are no capital markets, individuals cannot smooth consumption by saving, and therefore they will change their choice of fertility, schooling or both. ${ }^{28}$ It is not possible to determine $e_{t}$ and $N_{t}^{1}$ analytically as functions of the transfer, so that the values of the functions $U(A I D S, C V ; \cdot)$ and $U(N O A I D S, E V ; \cdot)$ must be determined numerically. In fact, the $\mathrm{CV}$ and $\mathrm{EV}$ can only be derived using grid search methods, ${ }^{29}$ which are computationally expensive, as they have to be done separately for each period, variation and scenario.

Note, also, that the CV and EV are likely to differ significantly, as the changes in mortality incurred when the epidemic breaks out are large. The difference stems from the fact that it is not only the the levels of consumption which change, but also the weights of the subutility functions. When computing the CV, we consider the AIDS utility function, when computing the EV, the NO AIDS one. These differ, for instance, in the weight attached to old-age consumption, $\beta_{1} \kappa_{t}$, which is much lower in the case of the CV. Hence, the $\mathrm{CV}$ will generally be much larger than the EV as mortality rates rise, and vice-versa.

The EV and CV being hard to compute, we will now turn to other, simpler, measures of welfare. One such measure is income, summed over all relevant individuals and periods. While income measures, to some extent, the utility which accrues to households through its close connection to consumption, it does not measure the utility that arises from the educational attainment of the individual's children (i.e. altruism), and it does not fully measure the disutility arising from premature mortality. The contribution of the altruism term to an individual's level of utility is less than $2 \%$ in all years, scenarios and variations analyzed; consumption, especially its distribution over time, and the parents' expectations about mortality determine the rest. Therefore, the major drawback of using income as a measure of welfare is that is does not fully capture the losses and gains arising from changes in mortality rates. If these changes are small, income can be used as an easy to compute measure of welfare.

\footnotetext{
${ }^{28}$ This argument also holds if parents receive the transfer when they are old, as borrowing is not possible. While it is possible that there will exist a tuple of transfers $T_{t}, T_{t+2}$ for which fertility and schooling both remain unchanged, it is very unlikely that these transfers will correspond to a CV or EV

${ }^{29}$ The procedure, in the case of the EV, is as follows: First, compute the levels of utility attained in the AIDS case. Second, use the NO AIDS utility function to calculate the optimal levels of fertility and education for each transfer $T$, and the ensuing level of utility. Third, choose that level of $T$ for which utility in the NO AIDS case with the transfer is equal to the level of utility in the AIDS case without the transfer. Steps two and three must be done separately for every year. The procedure in the case of the $\mathrm{CV}$ is similar. Both the EV and CV can be calculated analogously when evaluating the policy program $\mathbf{P}$.
} 
The results, however, require careful interpretation, for they depend on whether per capita or total income (GDP) is used. Total income can rise in two ways: either the number of individuals rises, while income per head is constant, or the income of each individual rises while the number of individuals remains constant. If parents decide to reduce schooling while increasing fertility, per capita income will be lower - suggesting that individuals might be worse off - while total income might rise - suggesting that an economy-wide indicator has improved. If such a tradeoff does not exist, as is the case when the HIV/AIDS epidemic first breaks out, ${ }^{30}$ both income per capita and total GDP are arguably acceptable measures of welfare. In the case of the policy program $\mathbf{P}$, however, such tradeoffs are frequent, in some cases per capita GDP falls while total GDP (and population) rise. Therefore, when per capita GDP is the measure of welfare, the policy program seems to have negative consequences. If total GDP is used instead, the program has positive consequences. Which measure, then, is better? Note that when the extended lifetime under the program is taken into consideration, the apparent negative effect of the program measured using per capita GDP dissapears. Consequently, both per capita income and total income can be used to measure the welfare losses incurred when the HIV/AIDS epidemic breaks out and the gains from the program.

One last aspect needs to be discussed, namely, the treatment of those individuals who are born under one program but not under another. The valuation of such individuals and their lives is the issue of a lively discussion in both philosophy and economics, and there is no commonly accepted method or procedure. Most authors who are concerned with AIDS, for instance, Young (2005), do not take such individuals into account. Note that whatever individual measure of welfare is chosen - CV, EV or per capita income - it has to be summed up over all households/individuals who experience the losses and gains in order to capture the full effects to be analyzed. Consider, for instance, the effects of the HIV/AIDS epidemic. When only those individuals who actually lived at some point of time are considered, the losses are underestimated: if there had been no epidemic, parents would have had more and better-educated children, whose hypothetical income and lives involve losses which need to be taken into account when measuring the effects of $\mathrm{HIV} / \mathrm{AIDS}$.

In the present paper, we need to estimate the effects of the HIV/ADS epidemic in the ab-

\footnotetext{
${ }^{30}$ Both per capita and total GDP are higher in the NO AIDS case compared to either AIDS scenario. The single exception is the period $t=10$, in which per capita GDP in the presence of the disease is somewhat higher than in its absence due to a rise in child labor. As the difference amounts to less than $1 \%$ in all cases, we will ignore this problem for the rest of the welfare analysis.
} 
sence of the intervention, when there is no tradeoff, and the effects of the policy program $\mathbf{P}$, when there is. Two measures of welfare will be employed, both of them based on individual incomes: first, a measure in which unborn individuals are taken into account, and second, one in which they are not. To compute the first measure, we calculate the income, in every period, of every individual alive in that period in the presence of the intervention or shock, and compare it to the total income of every individual in the absence of the intervention/shock. As the income of all individuals in some period is simply the total GDP of that period, the first method compares GDP levels. As argued before, this method is more appropriate when there is no tradeoff between schooling and fertility, that is, when comparing the NO AIDS and AIDS cases. To compute the second measure, we calculate the number of people who have died prematurely, or will do so, because of HIV/AIDS (or, respectively, who would have died if there had been no policy intervention), and assess their lost earnings. This step is somewhat more complicated than computing premature deaths. The simplest way of doing it is to assume that, even if the mortality rates had been different, these individuals would have enjoyed the same education, so that their level of human capital would remain unchanged. In this case, their lost earnings would be $\alpha_{t} \lambda^{a}$ for each adult in each decade, where $\lambda^{a}$ denotes her level of human capital. It is also possible, however, that the individual would have enjoyed more schooling, and hence a higher level of human capital, if mortality rates had been lower, and vice versa. As it is not possible to compute this hypothetical level of schooling, we will simply assume that $\lambda_{t}$ and $e_{t}$ take the same value as in the case without the HIV/AIDS mortality shock or the governmental intervention, as appropriate. Therefore, when computing the (monetary) losses, we will make two assumptions:

(A1) The fact that some potential children will never be born as a consequence of HIV/AIDS will be ignored

(A2) The level of human capital attained by all children will be either

(A2a) the same level as in the case where the shock/intervention takes place.

(A2b) the same level as in the case where the shock/intervention does not takes place

For all measures employed, we compute the 1990 net present value (NPV) of all losses and gains, and compare it either to the 1990 NPV of total, NO AIDS GDP, or to the 1990 NPV of the cost of the policy intervention $\mathbf{P}$, to assess the effects of the epidemic or the social profitability of the policy program. In all cases, the calculations are limited to the years 1990 to 2040, so that gains and losses which accrue after 2040 are not included. 


\section{Results}

The effects of the HIV/AIDS epidemic and the policy program $\mathbf{P}$ are discussed in sections 9.1 and 9.2 respectively. We will first present changes in some basic measures of welfare, namely, the adults' level of human capital, $\lambda_{t}$, per capita income, $y_{t}$, total GDP, $Y_{t}$ and population in the last period of the projections $(t=14)$. Second, we will determine the overall effects of the epidemic and the intervention using the procedures described above.

\subsection{No public spending on health}

The effects of the HIV/AIDS epidemic on the Kenyan people and economy are substantial, but they also depend on the way households react. The average ${ }^{31}$ levels of several simple measures of welfare as a percentage of their respective NO AIDS levels for the year 2040 are set out in tables 25 - 29 in the appendix, as well as in table 20 below. Figure 2 contains the levels of three measures relative to their NO AIDS levels, for all calibrations. While $\lambda$ and $y$ describe welfare at the individual level, GDP and population are aggregate measures. The effects of the epidemic on $\lambda$, per capita GDP and total GDP are strongest in the case where $e_{9}$ is revised in 1990, that is, in the first scenario. The impact of HIV/AIDS on GDP is a heavy one: it is lower by at least $34 \%$ in all cases, and up to $55 \%$ in the second variation. The effect of the HIV/AIDS epidemic on human capital and per capita GDP is by far strongest in the second variation, in which it is assumed that school fees are not abolished. In that case, parents reduce education sharply as the epidemic breaks out, and child labor persists at least until 2030. This variation is also the only case in which the effects of the epidemic on 2040 population are stronger in the second scenario compared to the first. With education being very expensive, and parents being comparatively poor in the first scenario, they prefer to invest in fertility (as opposed to schooling). As a consequence, total population is not reduced by as much in the first scenario as it is in the second, in which fertility is always lower, and education higher.

In the light of the results above, it is obvious that the abolition of school fees strongly mitigated the effects of the epidemic on all welfare measures, with the exception of total population, in both scenarios. The results of the other variations depart only slightly from those of the benchmark cases, with the differences amounting to no more than 4 percentage points, compared to $4-23$ percentage points in the second variation.

The overall effects of the epidemic are set out in tables 21 and 22 . Table 21 gives the 1990

\footnotetext{
${ }^{31}$ The levels reported in the tables refer to average effects for all 27 calibrations
} 

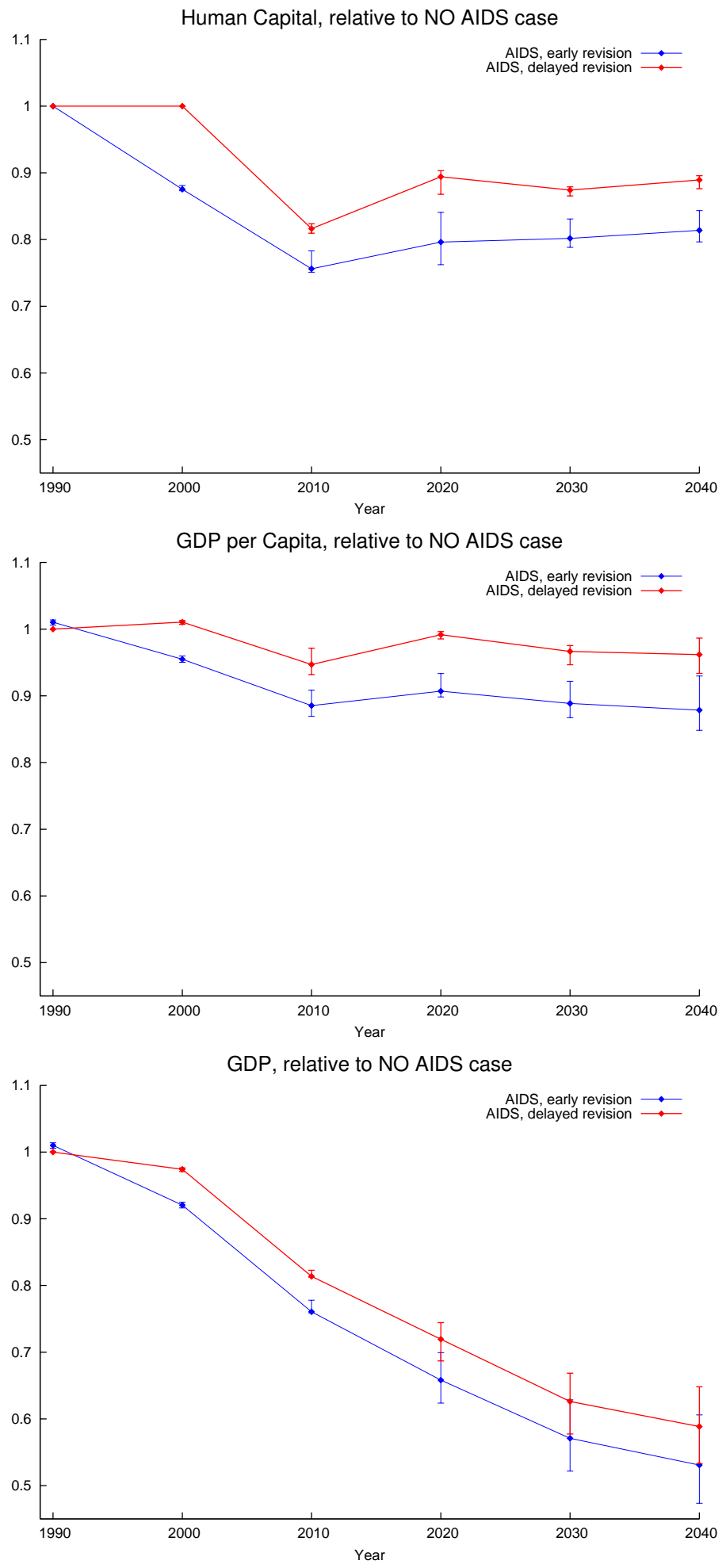

Figure 2: The effects of the HIV/AIDS epidemic expressed as a \% of the NO AIDS levels, all calibrations The bars denote the maximum/minimum values the ratio can take over all calibrations. 
Table 20: The effects of the HIV/AIDS epidemic expressed as a \% of the NO AIDS levels in 2040. Average Values

\begin{tabular}{|c|cccc|}
\hline & $\lambda$ & $\begin{array}{c}\text { GDP per cap. } \\
y\end{array}$ & GDP $Y$ & Population \\
\hline Base Case & & & & \\
\hline Scenario 1 & 81 & 88 & 53 & 60 \\
Scenario 2 & 89 & 96 & 59 & 61 \\
\hline Variation 1 $\left(N_{\min }^{1}\right)$ & & & & 62 \\
\hline Scenario 1 & 80 & 87 & 54 & 63 \\
Scenario 2 & 88 & 96 & 60 & 70 \\
\hline Variation 2 $\left(\sigma_{t \geq 10}\right)$ & & & & 64 \\
\hline Scenario 1 & 58 & 70 & 59 & 57 \\
Scenario 2 & 72 & 83 & 54 & 57 \\
\hline Variation 3 $\left(\alpha_{t \geq 10}\right)$ & & & & \\
\hline Scenario 1 & 83 & 89 & 55 & 62 \\
Scenario 2 & 89 & 96 & 55 & \\
\hline Variation 4 $\left(z_{t \geq 11}\right)$ & & & 60 & \\
\hline Scenario 1 & 82 & 90 & & \\
Scenario 2 & 89 & 97 &
\end{tabular}

Scenario 1: Revision of $e_{9}$

Scenario 2: Delayed Expectations

NPV of the overall losses as a fraction of the 1990 NPV of total NO AIDS GDP when unborn individuals are taken into account, for the base case. The variations are reported in the appendix.

Table 21: Lost income through premature adult mortality, including unborn individuals

\begin{tabular}{|l|cc|}
\hline Interest Rate & Scenario $1^{a}$ & Scenario $2^{b}$ \\
\hline $0.0 \%$ p.a. & 31 & 26 \\
$1.2 \%$ p.a. & 29 & 24 \\
$5.0 \%$ p.a. & 21 & 17 \\
\hline
\end{tabular}

${ }^{a}$ Renegotiation of $e_{9}$

${ }^{b}$ Delayed Expectations

Average values over all calibrations are reported. All values expressed as a \% of the 1990 NPV of total NO AIDS GDP between 1990 and 2040. 
Table 22: Lost income through premature adult mortality, excluding unborn individuals

\begin{tabular}{|l|cccc|}
\hline Interest Rate & \multicolumn{2}{|c}{ Scenario $^{a}$} & \multicolumn{2}{c|}{ Scenario $2^{b}$} \\
& $(\mathrm{~A} 2 \mathrm{a})$ & $(\mathrm{A} 2 \mathrm{~b})$ & $(\mathrm{A} 2 \mathrm{a})$ & $(\mathrm{A} 2 \mathrm{~b})$ \\
\hline $0.0 \%$ p.a. & 11 & 24 & 12 & 19 \\
0.7\% p.a. & 10 & 22 & 11 & 18 \\
5.0\% p.a. & 8 & 18 & 9 & 14 \\
\hline
\end{tabular}

${ }^{a}$ Renegotiation of $e_{9}$

${ }^{b}$ Delayed Expectations

All values expressed as a \% of the 1990 NPV of total NO AIDS GDP between 1990 and 2040

Table 22 gives the 1990 net present value (NPV) of the loss of income incurred through premature adult mortality as a fraction of the NPV of total GDP in the period 1990-2040, when unborn individuals are ignored, using assumptions (A2a) or (A2b). Three different annual rates of interest are considered: first, $r=0$; second, $r=0.7 \%$, which corresponds to the families' own pure discount rate, as computed from $\beta_{0}$ and $\beta_{1}$; and third, $r=5 \%$, which is the interest rate employed in Bell et. al (2004). As expected, the effects of the epidemic are stronger under assumption (A2b), as the levels of lost income per capita are higher in that case. Whichever scenario is chosen the effects of the epidemic range from $8 \%$ to $12 \%$ of total GDP under assumption (A2a), and 5 to 13 percentage points more under (A2b). Even when the incomes of unborn individuals are ignored, therefore, the society suffers significant economic losses when HIV/AIDS breaks out.

\subsection{Public Spending on Health}

The effects of the program P, expressed as a \% of the 2040 NO AIDS level, are set out in table 23. Figure 3 describes three welfare measures relative to their respective levels in the absence of the policy program, for all calibrations. In all variations, all measures of aggregate welfare are higher if the program is undertaken. The results for individual measures of welfare, however, are mixed: they are negative in some cases. To illustrate the changes induced by the policy program $\mathbf{P}$, consider the second scenario of the base case, the results of which are reported in table 13 the lower half of table 30 . Note that the level of human capital after 2030 in the presence of the program is somewhat lower than in its absence $(8.349<8.355)$, although the levels of schooling are identical in all periods. Recall that the level of human capital of a young adult depends on three variables: first, the quality of schooling $\left(z_{t}\right)$, second, the amount of time she spends at school $\left(e_{t}\right)$, and, third, the average level of human capital of her parents/teachers $\left(\frac{N_{t}^{2} \lambda_{t}+N_{t}^{3} \lambda_{t-1}}{N_{t}^{2}+N_{t}^{3}}\right)$. The pol- 

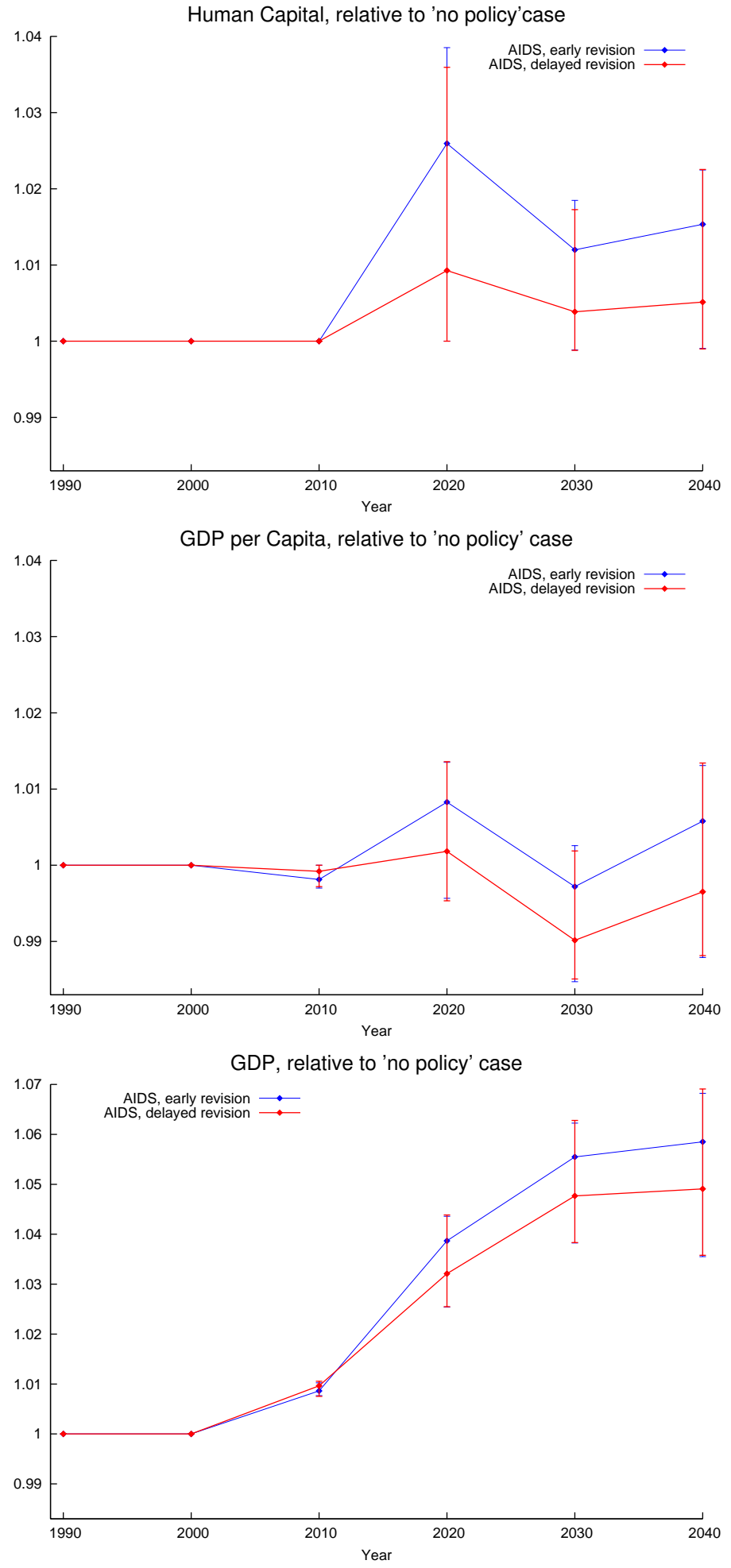

Figure 3: The effects of the HIV/AIDS epidemic expressed as a \% of the 'no policy' levels, all calibrations

The bars denote the maximum/minimum values the ratio can take over all calibrations. 
Table 23: The average effects of the public spending program $\mathbf{P}$, expressed as a percentage of the NO AIDS levels in 2040

\begin{tabular}{|c|cccc|}
\hline & $\lambda$ & $\begin{array}{c}\text { per capita } \\
\text { GDP } y\end{array}$ & GDP $Y$ & Population \\
\hline Base Case & \multicolumn{5}{|c|}{} & \\
\hline Scenario 1 & 1.5 & 0.6 & 5.8 & 5.2 \\
Scenario 2 & 0.5 & -0.4 & 4.9 & 5.3 \\
\hline Variation 1 $\left(N_{\text {min }}\right)$ & & & & 5.0 \\
\hline Scenario 1 & 2.0 & 1.1 & 6.2 & 5.1 \\
Scenario 2 & 1.2 & 0.3 & 5.4 & 3.2 \\
\hline Variation 2 $\left(\sigma_{t \geq 10}\right)$ & & & & 3.8 \\
\hline Scenario 1 & 5.3 & 3.4 & 6.7 & 7.7 \\
Scenario 2 & 5.7 & 3.3 & 7.2 & 7.8 \\
\hline Variation 3 $\left(\alpha_{t \geq 10}\right)$ & & & & 5.1 \\
\hline Scenario 1 & 0.2 & -0.4 & 7.3 & 5.2 \\
\hline Scenario 2 & 0.1 & -0.5 & & \\
\hline Variation 3 $\left(z_{t \geq 11}\right)$ & & & 4.5 & \\
\hline Scenario 1 & 0.4 & -0.6 & & \\
\hline Scenario 2 & -0.1 & -1.0 & & \\
\hline
\end{tabular}

Scenario 1: $e_{9}$ subject to a binding contract

Scenario 2: $e_{9}$ revised by the first group

icy program $\mathbf{P}$ does not change either $z_{t}$ nor $e_{t}$-it does, however, change $\frac{N_{t}^{2} \lambda_{t}+N_{t}^{3} \lambda_{t-1}}{N_{t}^{2}+N_{t}^{3}}$ : more adults in age group $a=3$ survive, so that the ratio of young, well-educated $(a=2)$ parents to older parents $(a=3)$ shifts, thereby reducing the average level of human capital of the teachers. The factor $\frac{N_{t}^{2} \lambda_{t}+N_{t}^{3} \lambda_{t-1}}{N_{t}^{2}+N_{t}^{3}}$, which determines $\lambda_{13}$, is 7.893 if the program is undertaken, and 7.898 otherwise, and, consequently, $\lambda_{13}$ is 8.349 in the presence of the program, and 8.355 in its absence. With human capital being lower when $\mathbf{P}$ is undertaken, the program can also have a negative impact on GDP per capita. In this case, another effect of the program also plays a role: with mortality rates reduced, parents assume that more of their children survive. As they cannot invest more in education - all children already enjoy full-time schooling - they have more children: for example, in the case mentioned before, each family has 1.28 children in 2030 in the absence of the program, and 1.32 in its presence. Consequently, the total population is higher, which reduces GDP per capita. As both effects can only be observed if schooling cannot be increased through the policy program, neither of them appears in the case where school fees are not abolished 
(Variation 2): here, the policy program leads to an increase in schooling, and its effects are strong and positive with respect to all measures of welfare. To sum up, the policy program $\mathbf{P}$ can have negative effects on individual measures of welfare as is shifts the structure of population, and thereby influences the intergenerational transfer of human capital. Note, however, that the negative effects are generally small, and amount to no more than $1.3 \%$. Recall also that mortality rates are reduced in the presence of the program, thereby extending life expectancy and therefore also the expected lifetime income. As a consequnce, the overall effect of the program on individuals might be positive even if per capita GDP is somewhat lower.

To assess the social profitability of the program $\mathbf{P}$, we employ the methods presented in section 8. Tables 40 and 41 in the appendix report the results when unborn individuals are, and are not, considered, respectively. Assumption (A2) from section 8 now reads as follows:

(A2) The level of human capital attained by all children will be either

(A2â) the same level as in the AIDS case with a policy program.

$(\mathrm{A} 2 \hat{b})$ the same level as in the AIDS case without a policy program.

Note that the levels of schooling and human capital are generally higher in the case of Assumption (A2 $\hat{a})$, so that the effects of the policy program $\mathbf{P}$ will also be higher in that case.

Even though in some cases the levels of human capital and GDP per capita were lower in the presence of the program than in its absence (see table 23), the program is always profitable, as people live longer. This effect strongly dominates the small reductions in human capital in all cases. Consequently, the discounted gains are at least three times as high as the discounted costs, so that the program is very profitable indeed. Note also that when computing the values in tables 40 and 41, we did not take into account the program's gains which accrue after 2040. More recent evidence suggests that the costs of saving a DALY through HAART might be lower than those employed in the present essay - in this case, the policy program would be even more profitable, as it saves and prolongs more lives. 


\section{Conclusion}

The HIV/AIDS epidemic in Kenya has had, and continues to have, a very damaging impact on the country's economy and population, both at the individual and at the aggregate level. Four factors play a major role in determining the long-term dynamics. First, there is the drop in the inter-generational transmission factor after 1970, which leads to a direct reduction in the formation of human capital and to levels of schooling. Second there is the reduction in labor productivity during the 1990s, as a consequence of which, fertility and total population both fall. Third, there is the increase in mortality rates after the full outbreak of the HIV/AIDS epidemic. Fourth, there is the reduction in education costs during the 2000s. The individuals' reaction to the epidemic depends, first, on when they realize its effects, and second on the social mechanisms governing the way exogenous shocks are dealt with. As has been argued in this essay, changes in the inter-generational transmission factor and the labor productivity factor can mitigate or intensify the epidemic's consequences. Similarly, measures aimed at changing $N_{\min }^{1}$ can also form part of an anti-AIDS program.

The policy program called $\mathbf{P}$, which is fully financed by foreign grants, has a positive effect on all aggregate-level welfare measures. In reaction to $\mathbf{P}$, parents normally increase the level of schooling their children enjoy, and therefore their future income and per capita GDP. Combining $\mathbf{P}$ with measures aimed at influencing $N_{m i n}^{1}, \alpha_{t}$ and/or $z_{t}$, can further mitigate the effects of the epidemic. Note, however, that comparing $\mathbf{P}$ with the other measures discussed in the variations is difficult, as the costs incurred in implementing the changes in the latter are unknown. The gains which accrue if $\mathbf{P}$ is undertaken outweigh many-fold the costs incurred in financing it, even if the overall returns to this investment that occur after 2040 are left out of account. 


\section{Appendix}

Table 24: Calibration Results: Averages

\begin{tabular}{|c|c|c|c|}
\hline$A=0.170(0.03)$ & $\epsilon=0.53(0.003)$ & $\eta=1.444(0.41)$ & \\
\hline$\mu=0.535(0.055)$ & $\chi=0.129(0.029)$ & $\begin{array}{c}b= \\
282.69(24.85)\end{array}$ & \\
\hline$\beta_{0}=1.7388(0.3968)$ & $\beta_{1}=1.5057(0.3444)$ & & \\
\hline \hline$t$ & $\lambda_{t}$ & $z_{t}$ & $\alpha_{t}$ \\
\hline 2 & $1.01(0)$ & $1.6861(0.066)$ & - \\
\hline 3 & $1.6714(0.023)$ & $1.6961(0.066)$ & - \\
\hline 4 & $2.2258(0.054)$ & $1.0198(0.019)$ & - \\
\hline 5 & $2.3984(0.050)$ & $1.0198(0.019)$ & $1417(303)$ \\
\hline 6 & $3.0289(0.078)$ & $1.0198(0.019)$ & $1417(303)$ \\
\hline 7 & $4.3109(0.135)$ & $1.0198(0.019)$ & $1417(303)$ \\
\hline 8 & $6.1433(0.240)$ & $0.5631(0.017)$ & $1417(303)$ \\
\hline 9 & $5.3279(0.286)$ & $0.5631(0.017)$ & $1417(303)$ \\
\hline 10 & $5.7249(0.365)$ & $0.5631(0.017)$ & $1152(244)$ \\
\hline
\end{tabular}

Standard Deviation in parentheses. 
Table 25: Summary of results, all calibrations: The Benchmark Cases

\begin{tabular}{|l|l|ccc|}
\hline \multicolumn{2}{|c|}{ Scenario 1: Renegotiation of $e_{9}$} & Average & Min. & Max. \\
\hline Deviation from census data $(2040)^{a}$ & NO AIDS & 1.22 & 1.10 & 1.36 \\
& AIDS & 1.11 & 1.08 & 1.15 \\
\hline Effect of the HIV/AIDS epidemic $(2040)^{b}$ & Population & 0.60 & 0.56 & 0.65 \\
& GDP & 0.53 & 0.47 & 0.61 \\
& GDP per capita & 0.88 & 0.85 & 0.93 \\
& Human Capital & 0.81 & 0.80 & 0.84 \\
\hline \hline \multicolumn{2}{|c|}{ Scenario 2: Delayed Expectations } & Average & Min. & Max. \\
\hline Deviation from census data (2040) $a$ & NO AIDS & 1.22 & 1.10 & 1.36 \\
Effect of the HIV/AIDS epidemic $(2040)^{b}$ & AIDS & 1.12 & 1.09 & 1.18 \\
\hline & Population & 0.61 & 0.57 & 0.66 \\
& GDP & 0.59 & 0.53 & 0.65 \\
& GDP per capita & 0.96 & 0.93 & 0.99 \\
Ratio of total 2040 population in the simulations to total 2040 population in the US
\end{tabular}

Bureau of Census data, as reported in tables 8 and 9 respectively.

$b \frac{\text { Population }_{t=14}^{A I D S}}{\text { Population }_{t=14}^{N O} A I D S}, \frac{Y_{t=14}^{A I D S}}{Y_{t=14}^{N O} A I D S}, \frac{y_{t=14}^{A I D}}{y_{t=14}^{N O} A I D S}, \frac{\lambda_{t=14}^{A I D S}}{\lambda_{t=14}^{N O} A I D S}$

Table 26: Summary of results, all calibrations: Variation 1

\begin{tabular}{|c|c|c|c|c|}
\hline \multicolumn{2}{|c|}{ Scenario 1: Renegotiation of $e_{9}$} & Average & Min. & Max. \\
\hline \multirow[t]{2}{*}{ Deviation from census data $(2040)^{a}$} & NO AIDS & 1.23 & 1.11 & 1.37 \\
\hline & AIDS & 1.15 & 1.12 & 1.19 \\
\hline \multirow[t]{4}{*}{ Effect of the HIV/AIDS epidemic $(2040)^{b}$} & Population & 0.62 & 0.57 & 0.67 \\
\hline & GDP & 0.54 & 0.48 & 0.63 \\
\hline & GDP per capita & 0.87 & 0.84 & 0.94 \\
\hline & Human Capital & 0.80 & 0.79 & 0.85 \\
\hline \multicolumn{2}{|c|}{ Scenario 2: Delayed Expectations } & Average & Min. & Max. \\
\hline \multirow{2}{*}{ Deviation from census data $(2040)^{a}$} & NO AIDS & 1.23 & 1.11 & 1.37 \\
\hline & AIDS & 1.16 & 1.13 & 1.22 \\
\hline \multirow[t]{4}{*}{ Effect of the HIV/AIDS epidemic $(2040)^{b}$} & Population & 0.63 & 0.59 & 0.67 \\
\hline & GDP & 0.60 & 0.54 & 0.67 \\
\hline & GDP per capita & 0.96 & 0.93 & 0.99 \\
\hline & Human Capital & 0.88 & 0.87 & 0.90 \\
\hline
\end{tabular}

Bureau of Census data, as reported in tables 8 and 9 respectively.

$b \frac{\text { Population }_{t=14}^{A I D S}}{\text { Population }_{t=14}^{N O}{ }^{A I D S}}, \frac{Y_{t=14}^{A I D S}}{Y_{t=14}^{N O A I D S}}, \frac{y_{t=14}^{A I D S}}{y_{t=14}^{N O}{ }^{A I D S}}, \frac{\lambda_{t=14}^{A I D S}}{\lambda_{t=14}^{N O}{ }^{A I D S}}$ 
Table 27: Summary of results, all calibrations: Variation 2

\begin{tabular}{|c|c|c|c|c|}
\hline \multicolumn{2}{|c|}{ Scenario 1: Renegotiation of $e_{9}$} & Average & Min. & Max. \\
\hline \multirow[t]{2}{*}{ Deviation from census data $(2040)^{a}$} & NO AIDS & 1.14 & 1.09 & 1.23 \\
\hline & AIDS & 1.20 & 1.13 & 1.31 \\
\hline \multirow[t]{4}{*}{ Effect of the HIV/AIDS epidemic $(2040)^{b}$} & Population & 0.70 & 0.68 & 0.71 \\
\hline & GDP & 0.49 & 0.47 & 0.55 \\
\hline & GDP per capita & 0.70 & 0.66 & 0.79 \\
\hline & Human Capital & 0.58 & 0.54 & 0.67 \\
\hline \multicolumn{2}{|c|}{$\begin{array}{ll}\text { Scenario 2: Delayed Expectations } \\
\end{array}$} & Average & Min. & Max. \\
\hline \multirow{2}{*}{ Deviation from census data $(2040)^{a}$} & NO AIDS & 1.14 & 1.09 & 1.23 \\
\hline & AIDS & 1.11 & 1.06 & 1.18 \\
\hline \multirow[t]{4}{*}{ Effect of the HIV/AIDS epidemic $(2040)^{b}$} & Population & 0.64 & 0.63 & 0.68 \\
\hline & GDP & 0.54 & 0.50 & 0.60 \\
\hline & GDP per capita & 0.83 & 0.79 & 0.89 \\
\hline & Human Capital & 0.72 & 0.68 & 0.78 \\
\hline
\end{tabular}

Bureau of Census data, as reported in tables 8 and 9 respectively.

$b \frac{\text { Population }_{t=14}^{A I D S}}{\text { Population }_{t=14}^{N O} A I D S}, \frac{Y_{t=14}^{A I D S}}{Y_{t=14}^{N O} A I D S}, \frac{y_{t=14}^{A I D S}}{y_{t=14}^{N O} A I D S}, \frac{\lambda_{t=14}^{A I D S}}{\lambda_{t=14}^{N O} A I D S}$

Table 28: Summary of results, all calibrations: Variation 3

\begin{tabular}{|c|c|c|c|c|}
\hline \multicolumn{2}{|c|}{ Scenario 1: Renegotiation of $e_{9}$} & Average & Min. & Max. \\
\hline \multirow[t]{2}{*}{ Deviation from census data $(2040)^{a}$} & NO AIDS & 1.50 & 1.32 & 1.71 \\
\hline & AIDS & 1.29 & 1.25 & 1.37 \\
\hline \multirow[t]{4}{*}{ Effect of the HIV/AIDS epidemic $(2040)^{b}$} & Population & 0.57 & 0.53 & 0.65 \\
\hline & GDP & 0.50 & 0.45 & 0.60 \\
\hline & GDP per capita & 0.89 & 0.86 & 0.92 \\
\hline & Human Capital & 0.83 & 0.81 & 0.84 \\
\hline \multicolumn{2}{|c|}{$\begin{array}{l}\text { Scenario 2: Delayed Expectations } \\
\end{array}$} & Average & Min. & Max. \\
\hline \multirow{2}{*}{ Deviation from census data $(2040)^{a}$} & NO AIDS & 1.50 & 1.32 & 1.71 \\
\hline & AIDS & 1.30 & 1.26 & 1.37 \\
\hline \multirow[t]{4}{*}{ Effect of the HIV/AIDS epidemic $(2040)^{b}$} & Population & 0.57 & 0.53 & 0.65 \\
\hline & GDP & 0.55 & 0.50 & 0.64 \\
\hline & GDP per capita & 0.96 & 0.94 & 0.98 \\
\hline & Human Capital & 0.89 & 0.89 & 0.90 \\
\hline
\end{tabular}

Bureau of Census data, as reported in tables 8 and 9 respectively.

$b \frac{\text { Population }_{t=14}^{A I D S}}{\text { Population }_{t=14}^{N O} A I D S}, \frac{Y_{t=14}^{A I D S}}{Y_{t=14}^{N O} A I D S}, \frac{y_{t=14}^{A I D S}}{y_{t=14}^{N O} A I D S}, \frac{\lambda_{t=14}^{A I D S}}{\lambda_{t=14}^{N O} A I D S}$ 
Table 29: Summary of results, all calibrations: Variation 4

\begin{tabular}{|c|c|c|c|c|}
\hline \multicolumn{2}{|c|}{ Scenario 1: Renegotiation of $e_{9}$} & Average & Min. & Max. \\
\hline \multirow{2}{*}{ Deviation from census data $(2040)^{a}$} & NO AIDS & 1.14 & 1.06 & 1.30 \\
\hline & AIDS & 1.06 & 1.03 & 1.11 \\
\hline \multirow{4}{*}{ Effect of the HIV/AIDS epidemic $(2040)^{b}$} & Population & 0.61 & 0.56 & 0.66 \\
\hline & GDP & 0.55 & 0.49 & 0.62 \\
\hline & GDP per capita & 0.90 & 0.86 & 0.94 \\
\hline & Human Cap & 0.82 & 0.81 & 0.84 \\
\hline \multicolumn{2}{|c|}{ Scenario 2: Delayed Expectations } & Average & Min. & Max. \\
\hline \multirow[t]{2}{*}{ Deviation from census data $(2040)^{a}$} & NO AIDS & 1.14 & 1.06 & 1.30 \\
\hline & AIDS & 1.07 & 1.04 & 1.12 \\
\hline \multirow[t]{4}{*}{ Effect of the HIV/AIDS epidemic $(2040)^{b}$} & Population & 0.62 & 0.57 & 0.66 \\
\hline & GDP & 0.60 & 0.55 & 0.66 \\
\hline & GDP per capita & 0.97 & 0.96 & 0.99 \\
\hline & Human Capital & 0.89 & 0.89 & 0.90 \\
\hline
\end{tabular}

${ }^{a}$ Ratio of total 2040 population in the simulations to total 2040 population in the US Bureau of Census data, as reported in tables 8 and 9 respectively.

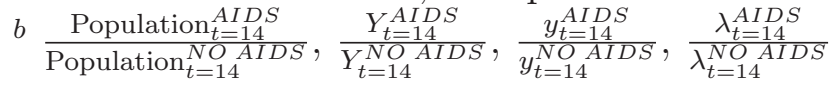

Table 30: The Policy Program P: Benchmark Case

\begin{tabular}{|l|cccccccc|}
\hline \multicolumn{7}{|c|}{ AIDS, Scenario 1: Revision of $e_{9}$} \\
\hline year $t$ & $\lambda_{t}$ & $N_{t}^{1}$ & $\frac{N_{t}^{1}}{\left(N_{t}^{2} N_{t}^{3}\right) / 2}$ & $e_{t}$ & $y_{t}$ & $Y_{t}\left(10^{7}\right)$ & Pop. & $E_{t} U$ \\
\hline 9 & 5.29 & 7182 & 1.87 & 0.42 & 1324 & 3107 & 23475 & 23.35 \\
10 & 4.97 & 8040 & 1.46 & 0.57 & 1186 & 3434 & 28944 & 21.91 \\
11 & 5.26 & 7107 & 1.05 & 0.98 & 1348 & 4196 & 31122 & 22.76 \\
12 & 6.71 & 7055 & 1.05 & 1.00 & 1502 & 5025 & 33445 & 23.73 \\
13 & 7.73 & 8295 & 1.29 & 1.00 & 1587 & 6000 & 37814 & 25.40 \\
14 & 9.14 & 9573 & 1.33 & 1.00 & 1776 & 7744 & 43602 & 27.09 \\
\hline \hline \multicolumn{7}{|c|}{ AIDS, scenario $2:$ Delayed Expectations } \\
\hline year $t$ & $\lambda_{t}$ & $N_{t}^{1}$ & $\frac{N_{t}^{1}}{\left(N_{t}^{2}+N_{t}^{3}\right) / 2}$ & $e_{t}$ & $y_{t}$ & $Y_{t}\left(10^{7}\right)$ & Pop. & $E_{t} U$ \\
\hline 9 & 5.29 & 7182 & 1.87 & 0.57 & 1310 & 3076 & 23475 & 26.47 \\
10 & 5.67 & 8040 & 1.46 & 0.59 & 1255 & 3634 & 28944 & 22.05 \\
11 & 5.69 & 7107 & 1.05 & 1.00 & 1446 & 4499 & 31122 & 22.98 \\
12 & 7.38 & 7055 & 1.05 & 1.00 & 1630 & 5451 & 33445 & 23.98 \\
13 & 8.35 & 8496 & 1.32 & 1.00 & 1711 & 6523 & 38113 & 25.67 \\
14 & 9.86 & 9840 & 1.35 & 1.00 & 1922 & 8493 & 44195 & 27.38 \\
\hline
\end{tabular}


Table 31: The Policy Program P: Variation 1: The level of $N_{\min }^{1}$

\begin{tabular}{|l|cccccccc|}
\hline \multicolumn{7}{|c|}{ AIDS, Scenario 1: Revision of $e_{9}$} \\
\hline year $t$ & $\lambda_{t}$ & $N_{t}^{1}$ & $\frac{N_{t}^{1}}{\left(N_{t}^{2}+N_{t}^{3}\right) / 2}$ & $e_{t}$ & $y_{t}$ & $Y_{t}\left(10^{7}\right)$ & Pop. & $E_{t} U$ \\
\hline 9 & 5.29 & 7182 & 1.87 & 0.42 & 1324 & 3107 & 23475 & 23.35 \\
10 & 4.97 & 8178 & 1.48 & 0.56 & 1179 & 3437 & 29155 & 21.91 \\
11 & 5.21 & 7518 & 1.10 & 0.93 & 1324 & 4216 & 31854 & 22.75 \\
12 & 6.51 & 7670 & 1.10 & 1.00 & 1455 & 5072 & 34857 & 23.70 \\
13 & 7.61 & 8466 & 1.22 & 1.00 & 1579 & 6170 & 39085 & 25.36 \\
14 & 8.97 & 9834 & 1.30 & 1.00 & 1751 & 7890 & 45055 & 26.95 \\
\hline \hline \multicolumn{7}{|c}{ AIDS, scenario $2:$ Delayed Expectations } & & \\
\hline year $t$ & $\lambda_{t}$ & $N_{t}^{1}$ & $\frac{N_{t}^{1}}{\left(N_{t}^{2}+N_{t}^{3}\right) / 2}$ & $e_{t}$ & $y_{t}$ & $Y_{t}\left(10^{7}\right)$ & Pop. & $E_{t} U$ \\
\hline 9 & 5.29 & 7182 & 1.87 & 0.57 & 1310 & 3076 & 23475 & 26.47 \\
10 & 5.67 & 8178 & 1.48 & 0.58 & 1248 & 3638 & 29155 & 22.04 \\
11 & 5.63 & 7518 & 1.10 & 1.00 & 1416 & 4509 & 31854 & 22.96 \\
12 & 7.34 & 7670 & 1.10 & 1.00 & 1594 & 5557 & 34857 & 23.97 \\
13 & 8.32 & 8681 & 1.25 & 1.00 & 1722 & 6785 & 39407 & 25.66 \\
14 & 9.83 & 10077 & 1.32 & 1.00 & 1923 & 8775 & 45626 & 27.29 \\
\hline
\end{tabular}

Table 32: The Policy Program P: Variation 2: Abolition of school fees

\begin{tabular}{|l|cccccccc|}
\hline \multicolumn{7}{|c|}{ AIDS, scenario 1: Revision of $e_{9}$} \\
\hline year $t$ & $\lambda_{t}$ & $N_{t}^{1}$ & $\frac{N_{t}^{1}}{\left(N_{t}^{2}+N_{t}^{3}\right) / 2}$ & $e_{t}$ & $y_{t}$ & $Y_{t}\left(10^{7}\right)$ & Pop. & $E_{t} U$ \\
\hline 9 & 5.29 & 7182 & 1.87 & 0.42 & 1324 & 3107 & 23475 & 23.35 \\
10 & 4.97 & 8040 & 1.46 & 0.37 & 1199 & 3471 & 28944 & 21.85 \\
11 & 4.37 & 7107 & 1.05 & 0.58 & 1278 & 3977 & 31122 & 22.48 \\
12 & 4.89 & 7684 & 1.14 & 0.66 & 1261 & 4335 & 34375 & 23.15 \\
13 & 5.19 & 9517 & 1.41 & 0.71 & 1202 & 4838 & 40248 & 24.51 \\
14 & 5.72 & 9968 & 1.24 & 0.89 & 1274 & 5854 & 45942 & 25.83 \\
\hline \hline & & & AIDS, scenario & $2:$ Delayed Expectations & & \\
\hline year $t$ & $\lambda_{t}$ & $N_{t}^{1}$ & $\frac{N_{t}^{1}}{\left(N_{t}^{2}+N_{t}^{3}\right) / 2}$ & $e_{t}$ & $y_{t}$ & $Y_{t}\left(10^{7}\right)$ & Pop. & $E_{t} U$ \\
\hline 9 & 5.29 & 7182 & 1.87 & 0.57 & 1310 & 3076 & 23475 & 26.47 \\
10 & 5.67 & 8040 & 1.46 & 0.38 & 1269 & 3673 & 28944 & 21.98 \\
11 & 4.70 & 7107 & 1.05 & 0.64 & 1363 & 4243 & 31122 & 22.69 \\
12 & 5.54 & 7055 & 1.05 & 0.79 & 1407 & 4707 & 33445 & 23.41 \\
13 & 6.07 & 8455 & 1.31 & 0.90 & 1381 & 5253 & 38052 & 24.85 \\
14 & 7.19 & 8940 & 1.23 & 1.00 & 1515 & 6488 & 42819 & 26.39 \\
\hline
\end{tabular}


Table 33: The Policy Program P: Variation 3: Recovery of $\alpha_{t}$

\begin{tabular}{|l|cccccccc|}
\hline \multicolumn{7}{|c|}{ AIDS, scenario 2: Delayed Expectations } \\
\hline year $t$ & $\lambda_{t}$ & $N_{t}^{1}$ & $\frac{N_{t}^{1}}{\left(N_{t}^{2}+N_{t}^{3}\right) / 2}$ & $e_{t}$ & $y_{t}$ & $Y_{t}\left(10^{7}\right)$ & Pop. & $E_{t} U$ \\
\hline 9 & 5.29 & 7182 & 1.87 & 0.42 & 1324 & 3107 & 23475 & 23.45 \\
10 & 4.97 & 8040 & 1.46 & 0.57 & 1186 & 3434 & 28944 & 22.00 \\
11 & 5.26 & 7494 & 1.11 & 1.00 & 1475 & 4673 & 31687 & 23.15 \\
12 & 6.76 & 8127 & 1.18 & 1.00 & 1615 & 5719 & 35401 & 24.19 \\
13 & 7.78 & 10463 & 1.47 & 1.00 & 1683 & 7136 & 42406 & 25.94 \\
14 & 9.22 & 12559 & 1.44 & 1.00 & 1916 & 9844 & 51376 & 27.50 \\
\hline \hline \multicolumn{7}{|c}{ AIDS, scenario $2:$ Delayed Expectations } & & \\
\hline year $t$ & $\lambda_{t}$ & $N_{t}^{1}$ & $\frac{N_{t}^{1}}{\left(N_{t}^{2}+N_{t}^{3}\right) / 2}$ & $e_{t}$ & $y_{t}$ & $Y_{t}\left(10^{7}\right)$ & Pop. & $E_{t} U$ \\
\hline 9 & 5.29 & 7182 & 1.87 & 0.57 & 1310 & 3076 & 23475 & 26.61 \\
10 & 5.67 & 8040 & 1.46 & 0.59 & 1255 & 3634 & 28944 & 22.14 \\
11 & 5.69 & 7551 & 1.12 & 1.00 & 1578 & 5014 & 31770 & 23.37 \\
12 & 7.38 & 8088 & 1.17 & 1.00 & 1753 & 6205 & 35397 & 24.43 \\
13 & 8.38 & 10690 & 1.50 & 1.00 & 1809 & 7734 & 42754 & 26.19 \\
14 & 9.90 & 12922 & 1.47 & 1.00 & 2060 & 10743 & 52140 & 27.78 \\
\hline
\end{tabular}

Table 34: The Policy Program P: Variation 4: Recovery of $z_{t}$

\begin{tabular}{|l|cccccccc|}
\hline \multicolumn{7}{|c|}{ AIDS, scenario 2: Delayed Expectations } \\
\hline year $t$ & $\lambda_{t}$ & $N_{t}^{1}$ & $\frac{N_{t}^{1}}{\left(N_{t}^{2}+N_{t}^{3}\right) / 2}$ & $e_{t}$ & $y_{t}$ & $Y_{t}\left(10^{7}\right)$ & Pop. & $E_{t} U$ \\
\hline 9 & 5.29 & 7182 & 1.87 & 0.42 & 1324 & 3107 & 23475 & 23.35 \\
10 & 4.97 & 8040 & 1.46 & 0.58 & 1186 & 3433 & 28944 & 21.96 \\
11 & 5.29 & 7107 & 1.05 & 1.00 & 1351 & 4203 & 31122 & 22.87 \\
12 & 7.69 & 7055 & 1.05 & 1.00 & 1586 & 5306 & 33445 & 23.97 \\
13 & 9.46 & 7650 & 1.19 & 1.00 & 1825 & 6726 & 36851 & 25.86 \\
14 & 12.22 & 8479 & 1.23 & 1.00 & 2199 & 9091 & 41348 & 27.76 \\
\hline \hline & & AIDS, scenario & $2:$ Delayed Expectations & & \\
\hline year $t$ & $\lambda_{t}$ & $N_{t}^{1}$ & $\frac{N_{t}^{1}}{\left(N_{t}^{2}+N_{t}^{3}\right) / 2}$ & $e_{t}$ & $y_{t}$ & $Y_{t}\left(10^{7}\right)$ & Pop. & $E_{t} U$ \\
\hline 9 & 5.29 & 7182 & 1.87 & 0.57 & 1310 & 3076 & 23475 & 26.47 \\
10 & 5.67 & 8040 & 1.46 & 0.60 & 1255 & 3633 & 28944 & 22.10 \\
11 & 5.72 & 7107 & 1.05 & 1.00 & 1449 & 4509 & 31122 & 23.09 \\
12 & 8.41 & 7055 & 1.05 & 1.00 & 1718 & 5747 & 33445 & 24.21 \\
13 & 10.21 & 7794 & 1.21 & 1.00 & 1969 & 7297 & 37066 & 26.12 \\
14 & 13.18 & 8672 & 1.25 & 1.00 & 2378 & 9935 & 41774 & 28.04 \\
\hline
\end{tabular}


Table 35: The effects of $\mathbf{P}$, all calibrations: The Benchmark Cases

\begin{tabular}{|c|c|c|c|c|}
\hline \multicolumn{2}{|c|}{ Scenario 1: Renegotiation of $e_{9}$} & Average & Min. & Max. \\
\hline \multirow[t]{4}{*}{ Effect of the Policy Program P $(2040)^{a}$} & Population & 5.2 & 4.8 & 5.6 \\
\hline & GDP & 5.8 & 3.5 & 6.8 \\
\hline & GDP per Capita & 0.6 & -1.2 & 1.3 \\
\hline & Human Capital & 1.5 & -0.1 & 2.3 \\
\hline \multicolumn{2}{|c|}{ Scenario 2: Delayed Expectations } & Average & Min. & Max. \\
\hline \multirow[t]{4}{*}{ Effect of the Policy Program $\mathbf{P}(2040)^{a}$} & Population & 5.3 & 4.8 & 5.6 \\
\hline & GDP & 4.9 & 3.6 & 6.9 \\
\hline & GDP per Capita & -0.4 & -1.2 & 1.3 \\
\hline & Human Capital & 0.5 & -0.1 & 2.2 \\
\hline
\end{tabular}

All values in $\%$

Table 36: The effects of $\mathbf{P}$, all calibrations: Variation 1

\begin{tabular}{|c|c|c|c|c|}
\hline \multicolumn{2}{|c|}{ Scenario 1: Renegotiation of $e_{9}$} & Average & Min. & Max. \\
\hline \multirow[t]{4}{*}{ Effect of the Policy Program $\mathbf{P}(2040)^{a}$} & Population & 5.0 & 4.6 & 5.5 \\
\hline & GDP & 6.2 & 3.4 & 6.6 \\
\hline & GDP per Capita & 1.1 & -1.2 & 1.3 \\
\hline & Human Capital & 2.0 & -0.1 & 2.4 \\
\hline \multicolumn{2}{|c|}{ Scenario 2: Delayed Expectations } & Average & Min. & Max. \\
\hline \multirow[t]{4}{*}{ Effect of the Policy Program P $(2040)^{a}$} & Population & 5.1 & 4.6 & 5.4 \\
\hline & GDP & 5.4 & 3.5 & 6.7 \\
\hline & GDP per Capita & 0.3 & -1.1 & 1.4 \\
\hline & Human Capital & 1.2 & -0.1 & 2.3 \\
\hline
\end{tabular}

All values in $\%$

Table 37: The effects of $\mathbf{P}$, all calibrations: Variation 2

\begin{tabular}{|c|c|c|c|c|}
\hline \multicolumn{2}{|c|}{ Scenario 1: Renegotiation of $e_{9}$} & Average & Min. & Max. \\
\hline \multirow[t]{4}{*}{ Effect of the Policy Program $\mathbf{P}(2040)^{a}$} & Population & 3.2 & 2.3 & 5.1 \\
\hline & GDP & 6.7 & 6.1 & 7.5 \\
\hline & GDP per Capita & 3.4 & 1.0 & 4.2 \\
\hline & Human Capital & 5.3 & 3.0 & 6.8 \\
\hline \multicolumn{2}{|c|}{ Scenario 2: Delayed Expectations } & Average & Min. & Max. \\
\hline \multirow{4}{*}{ Effect of the Policy Program P $(2040)^{a}$} & Population & 3.8 & 3.3 & 5.6 \\
\hline & GDP & 7.2 & 6.2 & 7.4 \\
\hline & GDP per Capita & 3.3 & 1.0 & 3.9 \\
\hline & Human Capital & 5.7 & 2.4 & 6.8 \\
\hline
\end{tabular}

All values in $\%$ 
Table 38: The effects of $\mathbf{P}$, all calibrations: Variation 3

\begin{tabular}{|c|l|ccc|}
\hline \multicolumn{2}{|c|}{ Scenario 1: Renegotiation of $e_{9}$} & Average & Min. & Max \\
\hline Effect of the Policy Program P $(2040)^{a}$ & Population & 7.7 & 5.9 & 9.1 \\
& GDP & 7.2 & 4.9 & 8.8 \\
& GDP per Capita & -0.4 & -1.0 & 0.3 \\
& Human Capital & 0.2 & 0.0 & 0.9 \\
\hline \multicolumn{2}{|c|}{ Scenario 2: Delayed Expectations } & Average & Min. & Max. \\
\hline \hline \multicolumn{2}{|c|}{ Effect of the Policy Program P (2040) } & $a$ \\
& Population & 7.8 & 5.9 & 9.1 \\
& GDP & 7.3 & 4.9 & 9.0 \\
& GDP per Capita & -0.5 & -0.9 & -0.1 \\
& Human Capital & 0.1 & 0.0 & 0.2 \\
\hline
\end{tabular}

$a \frac{\text { Population }_{t=14}^{A I D S, \mathbf{P}_{-P o p u l a t i o n}^{A I D S}}}{\text { Population }_{t=14}^{A I D S}}, \frac{Y_{t=14}^{A I D S}, \mathbf{P}_{-14} Y_{t=14}^{A I D S}}{Y_{t=14}^{A I D S}}, \frac{y_{t=14}^{A I D S}, \mathbf{P}_{-14} y_{t=14}^{A I D S}}{y_{t=14}^{A I D S}}, \frac{\lambda_{t=14}^{A I D S, \mathbf{P}}-\lambda_{t=14}^{A I D S}}{\lambda_{t=14}^{A I D S}}$.

All values in $\%$

Table 39: The effects of $\mathbf{P}$, all calibrations: Variation 4

\begin{tabular}{|c|c|c|c|c|}
\hline \multicolumn{2}{|c|}{ Scenario 1: Renegotiation of $e_{9}$} & Average & Min. & Max. \\
\hline \multirow[t]{4}{*}{ Effect of the Policy Program $\mathbf{P}(2040)^{a}$} & Population & 5.1 & 4.8 & 5.4 \\
\hline & GDP & 4.5 & 3.4 & 6.7 \\
\hline & GDP per Capita & -0.6 & -1.3 & 1.3 \\
\hline & Human Capital & 0.4 & -0.1 & 2.3 \\
\hline \multicolumn{2}{|c|}{ Scenario 2: Delayed Expectations } & Average & Min. & Max. \\
\hline \multirow[t]{4}{*}{ Effect of the Policy Program P $(2040)^{a}$} & Population & 5.2 & 4.8 & 5.3 \\
\hline & GDP & 4.1 & 3.5 & 4.4 \\
\hline & GDP per Capita & -1.0 & -1.3 & -0.9 \\
\hline & Human Capital & -0.1 & -0.1 & -0.1 \\
\hline
\end{tabular}

All values in $\%$ 
Table 40: The policy program P: Profitability ${ }^{a}$, including unborn individuals, all calibrations

\begin{tabular}{|c|c|c|c|c|c|c|}
\hline \multirow[t]{2}{*}{ Interest Rate } & \multicolumn{3}{|c|}{ Scenario 1} & \multicolumn{3}{|c|}{ Scenario 2} \\
\hline & Average & Min. & Max. & Average & Min. & Max. \\
\hline \multicolumn{7}{|l|}{ Base Case } \\
\hline $0.0 \%$ p.a. & 8 & 6 & 9 & 8 & 7 & 10 \\
\hline $0.7 \%$ p.a. & 7 & 6 & 8 & 7 & 6 & 9 \\
\hline $5.0 \%$ p.a. & 5 & 4 & 5 & 4 & 4 & 5 \\
\hline \multicolumn{7}{|c|}{ Variation 1: The level of $N_{\min }^{1}$} \\
\hline $0.0 \%$ p.a. & 9 & 6 & 9 & 9 & 7 & 10 \\
\hline $0.7 \%$ p.a. & 8 & 6 & 8 & 8 & 6 & 9 \\
\hline $5.0 \%$ p.a. & 5 & 4 & 5 & 5 & 4 & 5 \\
\hline \multicolumn{7}{|c|}{ Variation 2: The level of $\sigma_{t}$} \\
\hline $0.0 \%$ p.a. & 8 & 7 & 9 & 9 & 8 & 9 \\
\hline $0.7 \%$ p.a. & 7 & 7 & 8 & 8 & 7 & 8 \\
\hline $5.0 \%$ p.a. & 4 & 4 & 5 & 5 & 5 & 5 \\
\hline \multicolumn{7}{|c|}{ Variation 3: The level of $\alpha_{t}$} \\
\hline $0.0 \%$ p.a. & 13 & 11 & 15 & 14 & 12 & 16 \\
\hline $0.7 \%$ p.a. & 12 & 10 & 13 & 13 & 10 & 15 \\
\hline $5.0 \%$ p.a. & 7 & 6 & 8 & 8 & 6 & 9 \\
\hline \multicolumn{7}{|c|}{ Variation 4: The level of $z_{t}$} \\
\hline $0.0 \%$ p.a. & 8 & 6 & 10 & 7 & 7 & 8 \\
\hline $0.7 \%$ p.a. & 7 & 6 & 9 & 7 & 6 & 7 \\
\hline $5.0 \%$ p.a. & 4 & 4 & 6 & 4 & 4 & 4 \\
\hline
\end{tabular}

${ }^{a}$ All entries expressed as multiples of the 1990 NPV of the costs of $\mathbf{P}$.

Scenario 1: Revision of $e_{9}$

Scenario 2: Delayed Expectations 
Table 41: The policy program $\mathbf{P}$ : Profitability ${ }^{a}$, excluding unborn individuals, all calibrations

\begin{tabular}{|c|c|c|c|c|c|c|c|c|c|c|c|c|}
\hline Interest Rate & \multicolumn{6}{|c|}{ Scenario 1} & \multicolumn{6}{|c|}{ Scenario 2} \\
\hline & \multicolumn{3}{|c|}{$(\mathrm{A} 2 \hat{a})$} & \multicolumn{3}{|c|}{$(\mathrm{A} 2 \hat{b})$} & \multicolumn{3}{|c|}{$(\mathrm{A} 2 \hat{a})$} & \multicolumn{3}{|c|}{$(\mathrm{A} 2 \hat{b})$} \\
\hline & Avg & Min. & Max. & Avg & Min & Max. & Avg & Min. & Max. & Avg & Min & $\operatorname{Max}$. \\
\hline \multicolumn{13}{|l|}{ Base Case } \\
\hline $0.0 \%$ p.a. & 5 & 5 & 5 & 7 & 5 & 7 & 5 & 5 & 5 & 6 & 5 & 8 \\
\hline $0.7 \%$ p.a. & 4 & 4 & 5 & 6 & 4 & 7 & 5 & 4 & 5 & 5 & 4 & 7 \\
\hline $5.0 \%$ p.a. & 3 & 3 & 3 & 4 & 3 & 4 & 3 & 3 & 3 & 4 & 3 & 5 \\
\hline \multicolumn{13}{|c|}{ Variation 1: The level of $N_{\min }^{1}$} \\
\hline $0.0 \%$ p.a. & 5 & 5 & 5 & 7 & 4 & 8 & 5 & 5 & 5 & 7 & 5 & 8 \\
\hline $0.7 \%$ p.a. & 4 & 4 & 4 & 6 & 4 & 7 & 5 & 4 & 5 & 6 & 4 & 7 \\
\hline $5.0 \%$ p.a. & 3 & 3 & 3 & 4 & 3 & 4 & 3 & 3 & 3 & 4 & 3 & 5 \\
\hline \multicolumn{13}{|c|}{ Variation 1: The level of $\sigma_{t}$} \\
\hline $0.0 \%$ p.a. & 4 & 4 & 5 & 7 & 5 & 7 & 5 & 4 & 5 & 8 & 6 & 8 \\
\hline $0.7 \%$ p.a. & 4 & 4 & 4 & 6 & 5 & 6 & 4 & 4 & 4 & 7 & 5 & 7 \\
\hline $5.0 \%$ p.a. & 3 & 3 & 3 & 4 & 3 & 4 & 3 & 3 & 3 & 4 & 4 & 4 \\
\hline \multicolumn{13}{|c|}{ Variation 1: The level of $\alpha_{t}$} \\
\hline $0.0 \%$ p.a. & 5 & 5 & 6 & 6 & 5 & 7 & 6 & 5 & 6 & 6 & 5 & 6 \\
\hline $0.7 \%$ p.a. & 5 & 5 & 5 & 5 & 5 & 6 & 5 & 5 & 5 & 5 & 5 & 6 \\
\hline $5.0 \%$ p.a. & 3 & 3 & 4 & 4 & 3 & 4 & 4 & 3 & 4 & 4 & 3 & 4 \\
\hline \multicolumn{13}{|c|}{ Variation 1: The level of $z_{t}$} \\
\hline $0.0 \%$ p.a. & 5 & 5 & 5 & 6 & 5 & 8 & 5 & 5 & 6 & 5 & 5 & 6 \\
\hline $0.7 \%$ p.a. & 4 & 4 & 5 & 5 & 4 & 7 & 5 & 4 & 5 & 5 & 4 & 5 \\
\hline $5.0 \%$ p.a. & 3 & 3 & 3 & 3 & 3 & 5 & 3 & 3 & 4 & 3 & 3 & 3 \\
\hline
\end{tabular}

${ }^{a}$ All entries expressed as multiples of the 1990 NPV of the costs of $\mathbf{P}$.

Scenario 1: e subject to a binding contract

Scenario 2: $e_{9}$ revised by the first group 


\section{References}

[1] AEGIS (2003), Kenya-AIDS-deaths, AIDS Education Global Information System, http://www.aegis.com/news/afp/2003/AF031233.html

[2] Arndt, C. and Lewis, J. D. (2000), "The Macro Implications of HIV/AIDS in South Africa: A Preliminary Assessment", South African Journal of Economics, 68(5), 856-87.

[3] Barro, R. and Lee, J.W., (1996), "International Measures on Schooling Years and Schooling Quality", American Economic Review, Papers and Proceedings, 86(2): 218223.

[4] Bell, C., Devarajan, S. and Gersbach, H. (2003), "The Long-run Economic Costs of AIDS: Theory and an Application to South Africa", World Bank Policy Research Paper No. 3152, Washington, D.C..

[5] Bell, C., Gersbach, H., Bruhns, R., Völker, D. (2004), "Economic Growth, Human Capital and Population in Kenya in the Time of AIDS: A Long-run Analysis in Historical Perspective",mimeo, University of Heidelberg.

[6] Bell, C., Devarajan, S. and Gersbach, H. (2003), "Thinking about the Long-run Economic costs of HIV/AIDS", in M. Haacker (ed.), The Macroeconomics of HIV/AIDS, Washington, DC: IMF.

[7] Bloom, D. and Mahal, A. (1997), "AIDS, Flu and Black Death: Impacts on Economic Growth and Well-being", in D. Bloom and P. Godwin (eds.), The Economics of HIV and AIDS: The Case of South and South East Asia, New York: Oxford University Press.

[8] Bollinger, L., Stover, J. and Nalo, D. (1999), "The Economic Impact of AIDS in Kenya", The Futures Group International, Washington, DC.

[9] Chakraborty, S. and Das, M. (2005), "Mortality, Fertility, and Child Labor", Economics Letters, 86(2), 273-278.

[10] Corrigan, P., Glomm, G., and Mendez, F. (2004), "AIDS, Human Capital and Growth", mimeo.

[11] Corrigan, P., Glomm, G., and Mendez, F. (2005), "AIDS Crisis and Growth", Journal of Development Economics, 77 (1): 107-124. 
[12] Evenson, R.E., and Mwabu, G., (1995), "Household Composition and Expenditures on Human Capital Formation in Kenya", Economic Growth Center, Discussion Paper No. 731, Yale University.

[13] FAO (2005), FAO Country Profiles and Mapping Information System: Kenya, Online Database http://www.fao.org/countryprofiles/index.asp?ISO3=KEN\&lang=en

[14] Ferreira, P.C., and Pessoa, S. (2003), "The Long-Run Economic Impact of AIDS", mimeo.

[15] Gomez-Garcia, J. (2002), The Kenyalogy Guide, pp. 41-44. http://www.kenyalogy.com/eng/tienda/tienda.html

[16] Heston, A., Summers, R. and Aten, A., (2002), "Penn World Tables Version 6.1", Center for International Comparisons at the University of Pennsylvania (CICUP), October.

[17] Hoddinott, J. (1992), "Rotten Kids or Manipulative Parents: Are Children Old Age Security in Western Kenya", Economic Development and Cultura Change, 40 (3): 545565.

[18] I.L.O., (2002) Every Child Counts: New Global Estimates on Child Labour, I.L.O., Geneva.

[19] Kalemli-Ozcan, S. (2006), "AIDS, Reversal of the Demographic Transition and Economic Development: Evidence from Africa", University of Houston, mimeo.

[20] Kenya, Colony and Protectorate (1953), "Report on the Census of the Non-native Population of Kenya Colony and Protectorate taken in the Night of the 25th February, 1948", Government Printer, Nairobi.

[21] Kenya, Ministry of Economic Planning and Development, Statistics Division (1966), "Kenya Population Census 1962, Volume III, African Population", Government Printer, Nairobi.

[22] Kenya, Central Bureau of Statistics (1981), "Kenya Population Census, 1979", Government Printer, Nairobi.

[23] Kenya, Central Bureau of Statistics (1994), "Kenya Population Census, 1989", Government Printer, Nairobi. 
[24] Koukoumelis, A. (2005) "A more stable solution for the Kenya model", mimeo, Heidelberg University.

[25] Marseille, E., Hofmann, P.B., and Kahn, J.G. (2002), "HIV Prevention before HAART in Sub-Saharan Africa", The Lancet, 359: 1851-6.

[26] Omwego, A.,"The reality of HIV/AIDS in Africa: The case of East Africa.", http : //www.standwithafrica.org/hiv_aids/reality1.php

[27] Schweizer, U. (1996), "Welfare Economics of Population Growth", SFB 303 Discussion Paper No. A-535, Bonn University, Bonn.

[28] Sheffield, J. R. (1973), "Education in Kenya - An Historical Study", Teachers College Press, Columbia University.

[29] Thias, H., and Carnoy, M., (1972), "Cost-Benefit Analysis in Education: A Case Study of Kenya", World Bank Staff Occasional Paper No. 14, IBRD, Washington, D.C..

[30] U.N.AIDS (2002), Children on the Brink, 2002, U.N.AIDS, UNICEF and USAID collaboration, Geneva.

[31] U.N.AIDS (2004), Children on the Brink, 2004, U.N.AIDS, UNICEF and USAID collaboration, Geneva.

[32] U.N.AIDS (2004), Report on the Global HIV/AIDS Epidemic, 2004, New York.

[33] UNICEF (2005), Fertility and Contraceptive Use, http://www.childinfo.org/eddb/fertility/index.htm

[34] United Nations (1997), Sex and Age Distribution of the World Population: The 1996 Revision, Population Division, New York.

[35] United Nations (2004), World population Prospects, Online Database: http://esa.un.org/unpp/

[36] World Bank (2002). Education and HIV/AIDS - a window of hope, Washington, D.C.

[37] World Bank (2003). World Development Indicators, Washington, D.C.

[38] Young, A. (2005), "The Gift of the Dying: The Tragedy of AIDS and the Welfare of Future African Generations", The Quarterly Journal of Economics, 120(2), 423-466. 